\title{
Guidelines and Good Clinical Practice Recommendations for Contrast Enhanced Ultrasound (CEUS) in the Liver - Update 2020
}

WFUMB in Cooperation with EFSUMB, AFSUMB, AIUM, and FLAUS

\section{Aktualisierte Leitlinien und Empfehlungen für die gute klinische Praxis für CEUS der Leber}

\section{Authors}

Christoph F. Dietrich ${ }^{1,2 *}$, Christian Pállson Nolsøe ${ }^{3 *}$, Richard G. Barr ${ }^{4}$, Annalisa Berzigotti ${ }^{5}$, Peter N Burns ${ }^{6}$, Vito Cantisani ${ }^{7}$, Maria Cristina Chammas ${ }^{8}$, Nitin Chaubal ${ }^{9}$, Byung Ihn Choi ${ }^{10}$, Dirk-André Clevert ${ }^{11}$, Xinwu Cui ${ }^{12}$, Yi Dong ${ }^{13}$, Mirko D’Onofrio ${ }^{14}$, J. Brian Fowlkes ${ }^{15}$, Odd Helge Gilja ${ }^{16}$, Pintong Huang ${ }^{17}$, Andre Ignee ${ }^{18}$, Christian Jenssen ${ }^{19}$, Yuko Kono ${ }^{20}$, Masatoshi Kudo ${ }^{21}$, Nathalie Lassau ${ }^{22}$, Won Jae Lee ${ }^{23}$, Jae Young Lee ${ }^{24}$, Ping Liang ${ }^{25}$, Adrian Lim²6, Andrej Lyshchik ${ }^{27}$, Maria Franca Meloni ${ }^{28}$, Jean Michel Correas ${ }^{29}$, Yasunori Minami ${ }^{30}$, Fuminori Moriyasu ${ }^{31}$, Carlos Nicolau ${ }^{32}$, Fabio Piscagliaa ${ }^{33}$, Adrian Saftoiu ${ }^{34}$, Paul S. Sidhu ${ }^{35}$, Ioan Sporea ${ }^{36}$, Guido Torzilli37, Xiaoyan Xie ${ }^{38}$, Rongqin Zheng ${ }^{39}$

Affiliations

1 Department Allgemeine Innere Medizin (DAIM), Kliniken Hirslanden Beau Site, Salem und Permanence, Bern, Switzerland

2 Johann Wolfgang Goethe Universitätsklinik Frankfurt, Germany

3 Center for Surgical Ultrasound, Dep of Surgery, Zealand University Hospital, Køge. Copenhagen Academy for Medical Education and Simulation (CAMES). University of Copenhagen, Denmark

4 Department of Radiology, Northeastern Ohio Medical University, Rootstown, Ohio, USA and Southwoods Imaging, Youngstown, Ohio, USA

5 Hepatology, University Clinic for Visceral Surgery and Medicine, DBMR, Inselspital, University of Bern, Switzerland

6 Dept Medical Biophysics, University of Toronto, Imaging Research, Sunnybrook Research Institute, Toronto

7 Uos Ecografia Internistico-chirurgica, Dipartimento di Scienze Radiologiche, Oncologiche, Anatomo-Patologiche, Policlinico Umberto I, Univ. Sapienza, Rome, Italy

8 Institute of Radiology, Hospital das Clínicas, School of Medicine, University of São Paulo, Brazil

9 Thane Ultrasound Centre, Jaslok Hospital and Research Centre, Mumbai, India

10 Department of Radiology, Chung-Ang University Hospital, Seoul, Korea

11 Interdisciplinary Ultrasound-Center, Department of Radiology, University of Munich-Grosshadern Campus, Munich, Germany

12 Department of Medical Ultrasound, Tongji Hospital, Tongji Medical College, Huazhong University of Science and Technology, Wuhan China
13 Department of Ultrasound, Zhongshan Hospital,

Fudan University, Shanghai, China

14 Department of Radiology, G.B. Rossi University Hospital, University of Verona, Verona, Italy

15 Basic Radiological Sciences Division, Department of Radiology, University of Michigan Health System, Ann Arbor, MI, United States

16 National Centre for Ultrasound in Gastroenterology, Haukeland University Hospital, Bergen, and Department of Clinical Medicine, University of Bergen, Norway

17 Department of Ultrasound in Medicine, the Second Affiliated Hospital, Zhejiang University School of Medicine, Hangzhou, China

18 Department of Internal Medicine 2, Caritas Krankenhaus, Bad Mergentheim, Germany

19 Krankenhaus Märkisch Oderland, Department of Internal Medicine, Strausberg/Wriezen, Germany

20 Departments of Medicine and Radiology, University of California, San Diego, USA

21 Department of Gastroenterology and Hepatology, Kindai University Faculty of Medicine, Osaka, Japan

22 Imaging Department. Gustave Roussy and BIOMAPS. Université Paris-Saclay, Villejuif, France

23 Department of Radiology and Center For Imaging Science, Samsung Medical Center, Sungkyunkwan University School of Medicine, Seoul, Korea. Departments of Health and Science and Technology and Medical Device Management and Research, Samsung Advanced Institute for Health Science and Technology, Sungkyunkwan University, Seoul, Korea

24 Department of Radiology, Seoul National University College of Medicine, Seoul, Korea

25 Department of Interventional Ultrasound, Chinese PLA General Hospital, Beijing, China 
26 Department of Imaging, Imperial College London and Healthcare NHS Trust, Charing Cross Hospital Campus, London United Kingdom

27 Department of Radiology, Thomas Jefferson University Hospital, Philadelphia, PA, United States

28 Radiology Dept, University of Pavia, Milano, Italy

29 Service de Radiologie Adultes, Hôpital Necker, Université Paris Descartes, Paris, France

30 Department of Gastroenterology and Hepatology, Kindai University Faculty of Medicine, Osaka, Japan

31 Center for Cancer Ablation Therapy, Sanno Hospital, International University of Health and Welfare, Tokyo, Japan

32 Radiology Department, Hospital Clinic. University of Barcelona, Barcelona, Spain

33 Unit of Internal Medicine, Dept of Medical and Surgical Sciences, University of Bologna S. Orsola-Malpighi Hospital, Bologna, Italy

34 Research Center of Gastroenterology and Hepatology Craiova, University of Medicine and Pharmacy Craiova, Romania

35 Department of Radiology, King's College Hospital, King's College London, London

36 Department of Gastroenterology and Hepatology, University of Medicine and Pharmacy "Victor Babes", Timisoara, Romania

37 Department of Surgery, Division of Hepatobiliary \& General Surgery, Humanitas University \& Research Hospital, Rozzano, Milano, Italy

38 Department of Medical Ultrasonics, Institute of Diagnostic and Interventional Ultrasound, The First Affiliated Hospital of Sun Yat-Sen University, Guangzhou, China

39 Department of Ultrasound, The 3rd Affiliated Hospital of Sun Yat-sen University, Guangzhou, China

Key words

contrast enhanced ultrasound (CEUS), World Federation for Ultrasound in Medicine and Biology (WFUMB), guideline, liver

received 30.04 .2020

accepted 12.05.2020
Bibliography

Ultraschall in Med 2020; 41: 562-585

Published online: July 24, 2020

DOI $10.1055 / a-1177-0530$

ISSN $0172-4614$

(C) 2020. Thieme. All rights reserved.

Georg Thieme Verlag KG, Rüdigerstraße 14,

70469 Stuttgart, Germany

Correspondence

Prof. Dr. med. Christoph F. Dietrich

Department Allgemeine Innere Medizin (DAIM), Kliniken

Hirslanden Beau Site, Salem und Permanence, Bern,

Switzerland

Tel.: ++41/31/3353333

Fax: $++41 / 31 / 3353333$

c.f.dietrich@googlemail.com

\section{ABSTRACT}

The present, updated document describes the fourth iteration of recommendations for the hepatic use of contrast enhanced ultrasound (CEUS), first initiated in 2004 by the European Federation of Societies for Ultrasound in Medicine and Biology (EFSUMB). The previous updated editions of the guidelines reflected changes in the available contrast agents and updated the guidelines not only for hepatic but also for non-hepatic applications.

The 2012 guideline requires updating as previously the differences of the contrast agents were not precisely described and the differences in contrast phases as well as handling were not clearly indicated. In addition, more evidence has been published for all contrast agents. The update also reflects the most recent developments in contrast agents, including the United States Food and Drug Administration (FDA) approval as well as the extensive Asian experience, to produce a truly international perspective.

These guidelines and recommendations provide general advice on the use of ultrasound contrast agents (UCA) and are intended to create standard protocols for the use and administration of UCA in liver applications on an international basis to improve the management of patients.

\section{Introduction}

The present, updated document describes the fourth iteration of recommendations for the hepatic use of contrast enhanced ultrasound (CEUS), which was initiated by the European Federation of Societies for Ultrasound in Medicine and Biology (EFSUMB) [1]. The previous updated editions of the guidelines reflected changes in the available ultrasound contrast agents (UCAs) and updated the guidelines not only for hepatic but also non-hepatic applications [2-5].

The 2012 guideline requires updating as previously the differences of the contrast agents were not precisely described, evidence based recommendations not given and the differences in contrast phases as well as handling were not clearly indicated. In addition, more evidence has been published for all contrast agents. This update also reflects the most recent developments in contrast agents, including the US Food and Drug Administration (FDA) approval as well as the extensive Asian experience, to produce a truly international perspective.

The requirement for worldwide guidelines on the use of CEUS in the liver instigated the World Federation for Ultrasound in Medicine and Biology (WFUMB) to facilitate discussions, in conjunction with its component Federations, namely the Asian Federation of Societies for Ultrasound in Medicine and Biology (AFSUMB), American Institute of Ultrasound in Medicine (AIUM), Australasian Society for Ultrasound in Medicine (ASUM), Federation of Latin 
America Ultrasound (FLAUS) and EFSUMB and in collaboration with the International Contrast Ultrasound Society (ICUS), to bring the 2012 liver guidelines up-to-date, recognizing the fact that UCAs are now licensed in increasing parts of the world. Of the 38 authors, 19 were from 9 European countries representing EFSUMB, 13 from China, Japan, Korea and India representing AFSUMB, 5 from the USA representing AIUM, and 1 from MASU and FLAUS.

As for the previous guidelines, this document is based on comprehensive literature surveys, including results from prospective clinical trials. We followed an EFSUMB Policy Document on development strategy for clinical practice guidelines, position statements and technological reviews adopted by WFUMB [6]. For each key topic, the authors performed a systematic literature search based on an explicit search strategy using Medline, Cochrane library and, if appropriate, further defined databases/sources. The search strategy was predefined with regard to sources (e. g. Medline), inclusion criteria (e. g. language of the publication, time period, study type, full publication), exclusion criteria and search terms. The evidence used to substantiate recommendations were summarized in evidence tables including information on study type (e.g. systematic review and meta-analysis, RCT, prospective/ retrospective cohort study with defined outcome parameters, case series), case numbers, important outcomes and limitations. On topics where no significant study data were available, evidence was obtained from expert committee reports or was based on the consensus of experts in the field of ultrasound (US) and CEUS during the consensus conferences. Recommendations have been prepared in task force groups and finally discussed and voted on in a meeting of CEUS experts held in Granada in June 2019. Level of evidence (LoE) was assigned to recommendations based on evidence tables.

This joint effort has again resulted in simultaneous publication in the official journals of WFUMB and EFSUMB (i. e., Ultrasound in Medicine and Biology and Ultraschall in der Medizin/European Journal of Ultrasound).

These guidelines and recommendations provide general advice on the use of UCAs. They are intended to create standard protocols for the use and administration of UCAs in liver applications on an international basis, and improve the management of patients. Individual cases must be managed on the basis of all clinical data available.

\section{World-wide commercial availability of Ultrasound Contrast agents}

Availability of UCA for clinical use is based on the approval by regulatory agencies specific to the territory of intended use. Currently there are four agents that are available internationally for the use in the liver, listed here with their manufacturers.

- Definity/Luminity - Lantheus Medical Imaging, Inc., North Billerica, MA, US

- SonoVue/Lumason - Bracco Suisse SA, Geneva, Switzerland

- Optison - GE Healthcare AS, Oslo, Norway

- Sonazoid - GE Healthcare AS, Oslo, Norway
The approval of these agents varies throughout the world along with the approved indications. ICUS in collaboration with WFUMB has developed an interactive map ( $\bullet$ Fig. 1).

\section{Indications, contraindications, safety considerations}

The indications and contraindications are different among different UCAs; detailed information can be found in the official package insert of the drug.

\section{Safety considerations}

UCAs can be administered safely in various applications with minimal risk to patients [4, 7-11]. They are not excreted through the kidneys and can be safely administered to patients with renal insufficiency with no risk of contrast-related nephropathy or nephrogenic systemic fibrosis. There is no additional need for biochemical assessment or fasting prior to injection, and there is no evidence of any effect on thyroid function, as UCAs do not contain iodine [2, 3]. UCAs have a very low rate of anaphylactoid-type reactions (1/7000 patients, corresponding to $14 / 100000$, or $0.014 \%)[7,11-13]$ significantly lower than the rate with current iodinated computed tomography (CT) agents (35-95/100 000 patients, $0.035-0.095 \%$ ) [14] and gadolinium-based contrast agents at 4/64 (6.3 5) [15]. Serious anaphylactoid-type reactions to UCAs are observed in approximately $1 / 10000$ exposures, $0.01 \%[5,11]$.

SonoVue data pooled from 75 completed studies (of 6307 patients) in Europe, North America and Asia showed that the most frequent adverse events were headache $(2.1 \%)$, nausea $(0.9 \%)$, chest pain $(0.8 \%)$, and chest discomfort $(0.5 \%)$. All other adverse events occurred at a frequency of less than $0.5 \%$ [16]. Most adverse events were mild and resolved spontaneously within a short time without sequelae. Most cases of allergy-like events and hypotension occurred within a few minutes following injection of the agent. The overall reported rate of fatalities attributed to SonoVue, is low (14/2447 083 exposed patients; $0.0006 \%$ ) and compares favorably with the risk for fatal events reported for iodinated contrast agents (approximately $0.001 \%$ ). In all reported fatalities after use of an UCA, in both cardiac and non-cardiac cases, an underlying patient medical circumstance played a major role in the fatal outcome.

The intravesical administration of UCAs has been evaluated in a total of 7082 children described in 15 studies and in a European survey of 4131 children with $0.8 \%$ reported adverse events, mostly related to bladder catheterization $[17,18]$. Intravenous CEUS is also used in the pediatric population [19] and in numerous other documented areas [5]. The Food and Drug Administration (FDA) in the United States of America (USA) recently approved the use of Lumason for pediatric liver imaging [20], which is an important development. This application is, however, still off label in pediatric imaging in many countries. A significant reduction of ionizing radiation exposure is likely to be achieved in many areas by using CEUS in pediatric patients $[19,21]$. 


\section{Global Contrast-Enhanced Ultrasound}

\section{(CEUS)}

\section{Click on any country shaded in orange to see the commercially available agent(s).}

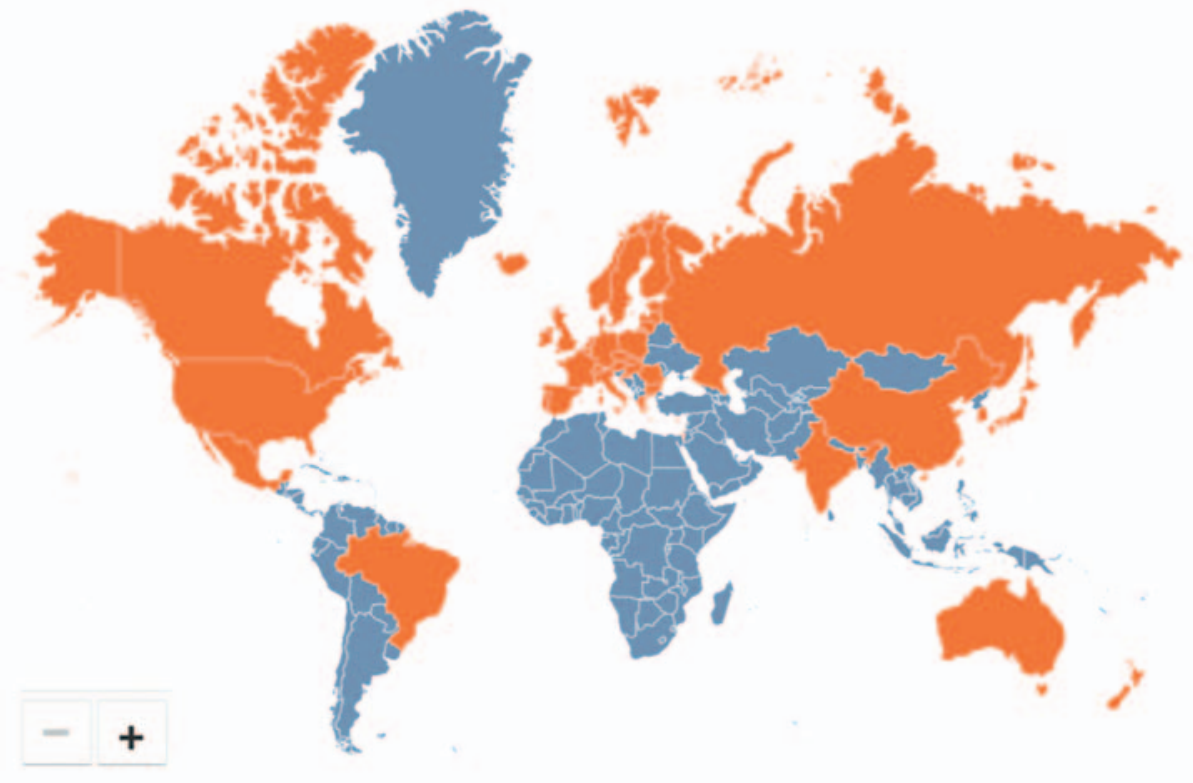

(Agent(s) commercially available)

(No agent commercially available at this time)

\footnotetext{
- See package inserts for approved indications. Note that this "Global CEUS" map lists certain ultrasound contrast agents under different product names (i.e, Lumason/SonoVue and Definity/Luminity). ICUS will update this map as additional agents are approved throughout the world.
}

- Fig. 1 Approval status of ultrasound contrast agents. The International Contrast Ultrasound Society (ICUS) in collaboration with WFUMB has developed an interactive map on the approval status of contrast agents. An updated version of this map can be found online (http://icus-society.org).

Most recently it was shown that the use of SonoVue appears to be safe in pregnant women [22].

\section{RECOMMENDATION 1}

Intravenous use of UCAs in adult populations is safe (LoE 2) (Pro 28, Abs 0, Against 0).

\section{RECOMMENDATION 2}

Intravenous use of UCAs in pediatric populations is safe (LoE 3) (Pro 28, Abs 0, Against 0).

\section{RECOMMENDATION 3}

Intracavitary use of UCAs is safe (LoE 2) (Pro 27, Abs 1, Against 0).

\section{Liver CEUS: Scanning technique and basic} image interpretation

The study procedure is well documented in previous CEUS Guidelines $[2,3]$ and has been described in detail in a recent WFUMB position paper [23]. Prior to performing a liver CEUS study, it is necessary to review the patient's clinical history, laboratory data and any prior imaging findings $[2,3]$. 
- Table 1 Vascular phases in CEUS of the liver (visualization post injection time).

\begin{tabular}{|l|l|l|}
\hline phase & start $\mathbf{( s e c )}$ & end $(\mathbf{s e c})$ \\
\hline arterial & $10-20$ & $30-45$ \\
\hline portal venous & $30-45$ & 120 \\
\hline late & $>120$ & $\begin{array}{l}\text { bubble disappearance } \\
\text { (approx. 4-8 min) }\end{array}$ \\
\hline post vascular & $>8$ min & approx. 30 min \\
\hline
\end{tabular}

\section{Study procedure}

Before CEUS, cysts and calcifications must be identified by conventional US, since these structures do not exhibit contrast enhancement and could therefore be erroneously interpreted as a malignant infiltration if only scanned in the late phase (LP). When cysts are missed by the baseline examination, it is necessary to carefully review both the contrast and the reference image, and to analyze the B-mode pattern of the liver tissue after the disappearance of the microbubbles.

\section{Image interpretation}

CEUS of the liver has three overlapping vascular phases after the injection of UCA, because of the dual blood supply of the liver, i. e. hepatic artery and portal vein (respectively $25 \%-30 \%$ and $70 \%-$ $75 \%$ of liver blood flow in non-cirrhotic conditions) ( $\bullet$ Table 1 ).

- The arterial phase (AP) provides information on the degree and pattern of the arterial vascular supply of a focal liver lesion (FLL). Early arterial enhancement pattern and vascular architecture are best seen in slow replay of a stored cine loop.

- The portal venous phase (PVP) represents the arrival of UCA through the portal system, resulting in diffuse and maximal enhancement of normal liver parenchyma.

- The late phase (LP) lasts until the clearance of the UCA from the circulation and depends on the type and dose of UCA, total scanning time, acoustic power output and on the sensitivity of the US system.

- The post-vascular phase is only observed with Sonazoid and represents uptake of the UCA by phagocytotic cells, e. g. Kupffer cells.

Slight/moderate variations of timing may occur, particularly in the case of cardiac dysfunction and in patients with vascular liver disease.

Vascular architecture and phase-specific contrast enhancement of the lesion compared to the adjacent liver parenchyma are the most important diagnostic features for the characterization of FLLs [2, 3].

\section{Differences between CEUS and other contrast- enhanced imaging modalities (CECT, CEMRI)}

UCAs comprise gas-filled particles (microbubbles) and differ in fundamental respects from the agents used in contrast enhanced
CT (CECT) and contrast enhanced magnetic resonance imaging (CEMRI), and for this reason play a complementary problem-solving role for indeterminate FLLs. Unlike CT and MR agents, microbubbles are not excreted by the kidneys. With the exception of Sonazoid, UCAs are purely intravascular agents. Therefore, CEUS should be considered as the first contrast imaging modality in patients with renal insufficiency. UCAs can be safely administrated more than once during the same examination. While the dynamic phases of liver enhancement with UCA resemble those of CECT with iodinated agents and CEMRI with gadolinium chelates, imaging is real-time with US. Other important differences exist and are well described in the literature [24-27]. For FLL characterization, an overall improvement in sensitivity and specificity is found for CEUS over CECT [28-33]. CEUS, in addition, is reported to be invaluable in providing characterization of indeterminate FLL on CT, MR imaging and positron emission tomography (PET) [34-36]. It is also reported that CEUS should be the subsequent imaging modality for all CT- and MR-indeterminate nodules before biopsy is undertaken [37].

\section{RECOMMENDATION 4}

CEUS is recommended in patients with inconclusive findings at CT or MR imaging (LoE 2, strong recommendation) (Pro 30, Abs 0, Against 1).

\section{RECOMMENDATION 5}

CEUS should be considered as first contrast imaging modality in patients with renal insufficiency (LoE 5, strong recommendation) (Pro 31, Abs 0, Against 0).

\section{Detection of malignant FLL: Transabdominal approach}

Conventional US is the most frequently used modality for the primary imaging of abdominal organs, including the liver, but is less sensitive in the detection of FLL than CECT, CEMRI or intraoperative US. A number of studies [38-47] have reported that CEUS has a considerably higher sensitivity of up to $80 \%-90 \%$ in detecting liver metastases, comparable to that of CECT [48] and CEMRI [40]. Furthermore, some reports have shown that CEUS is of particular usefulness with metastases $\leq 10 \mathrm{~mm}[49,50]$. CEUS has dramatically increased the capability of US for detection of FLL and has the potential to be incorporated into the diagnostic algorithm for malignant FLL.

\section{Study procedures}

The study procedure is described above. A second contrast administration (reinjection technique) can be used to confirm the metastatic nature of focal areas of contrast washout by demonstrating AP enhancement within the areas of contrast washout. 


\section{Detection of metastatic lesions}

The typical and almost invariable appearance of metastases is focal contrast washout. The enhancement patterns observed during the AP has limited clinical utility in lesion detection [2, 3, 23].

With vascular phase agents (SonoVue/Lumason, Definity/ Luminity, Optison), several studies have shown that the accuracy in the detection of liver metastases is comparable to that of CECT and CEMRI, when scanning conditions allow a complete imaging of all liver segments [44]. However, it should be noted that most of the studies have used initial and/or follow-up imaging (mostly CT examinations and sometimes MR imaging, and intra-operative US) as a reference standard, and very few reports include histologic or pathologic confirmation. Nonetheless, as CT and MR imaging are currently the modalities of choice for metastatic FLL detection, comparison of CEUS with these techniques seems reasonable in evaluating the diagnostic efficacy of CEUS. In addition, histologic confirmation of every malignant FLL in patients with clear imaging diagnosis might not be ethically appropriate. According to a meta-analysis including 828 metastases from 18 studies, overall sensitivity of CEUS for diagnosis of metastases was $91 \%$ (95\% Cl: 87-95\%) [30].

\section{RECOMMENDATION 6}

CEUS can be used for liver metastases detection as part of multimodality imaging approach (LoE 2, weak recommendation) (Pro 31, 0 Abs, 0 Against).

\section{Detection of hepatocellular carcinoma (HCC) and intrahepatic cholangiocellular carcinoma (ICC)}

With all UCAs, most HCC show AP hyperenhancement (APHE), but the short duration of APHE makes adequate assessment of the whole liver impracticable. The LP lasts long enough for a detailed examination, but the appearances of HCC are variable. Importantly, not all HCCs demonstrate contrast washout in the LP, limiting the sensitivity of CEUS for HCC detection. CEUS for staging of $\mathrm{HCC}$ is not recommended except for patients with portal vein tumor thrombus [51, 52].

With the post-vascular phase UCA (Sonazoid), scanning the entire liver at $10 \mathrm{~min}$ or later after injection helps to detect malignant nodules since typical HCC shows as an enhancement defect [5358]. However, approximately half of well differentiated HCCs do not show enhancement defects in the post-vascular phase [124].

ICCs behave in virtually the same manner as metastases, washing out rapidly and appearing as defects in the LP, regardless of the appearance in the AP [59]. This pattern may facilitate detection of satellite nodules adjacent to a larger lesion that were not visualized on conventional US.

\section{RECOMMENDATION 7}

Routine use of CEUS for the surveillance of patients at risk for HCC is not recommended (LoE 4, strong recommendation) (Pro 29, Against 2, Abs 0).

\section{RECOMMENDATION 8}

Routine use of CEUS for staging of HCC is not recommended (LoE 2, strong recommendation), (Pro 31, Against 0, Abs 0).

\section{CEUS for characterization of focal liver lesions}

Before starting liver CEUS, it is necessary to review the patient's clinical history, laboratory data and any prior imaging. The entire liver and the FLL should be interrogated using conventional B-Mode and color Doppler US in order to obtain reproducible information regarding segmental localization, size and relation to vessels and other anatomical landmarks as well as to guarantee optimal examination quality and ascertain whether underlying cirrhosis is present. The range of tumor types differs between cirrhotic and non-cirrhotic livers, with description of the characterization of FLL discussed separately for each.

\section{RECOMMENDATION 9}

Before performing CEUS to characterize FLLs, it is recommended to perform a systematic liver examination using B-Mode and Doppler US (LoE 5, strong recommendation) (Pro 32, Abs 0, Against 0).

\section{Characterization of FLL in the non-cirrhotic liver}

The probability of a FLL being benign (including inflammatory) or malignant depends on the symptoms and past medical history. An incidentally detected FLL in otherwise healthy and asymptomatic persons is likely benign $[60,61]$, whereas with pre-existing malignant disease, the probability of malignancy is significantly higher [1]. In patients with supportive symptomatology, FLLs may raise suspicion for phlegmonous inflammation or abscess formation.

The primary aim of CEUS in patients with a non-cirrhotic liver is to differentiate benign from malignant FLLs [29, 33, 45, 56-58, 62-78]. Thus, CEUS is useful to facilitate the clinical decision as to whether a sonographically detected liver lesion needs further investigation or surgery [79].

\section{RECOMMENDATION 10}

CEUS is recommended as the first-line imaging technique for the characterization of incidentally detected, indeterminate FLL at US in patients with non-cirrhotic liver and without a history or clinical suspicion of malignancy (LoE 1, strong recommendation) (Pro 30, Abs 2, Against 0). 


\section{RECOMMENDATION 11}

CEUS is suggested as the first-line imaging technique for the characterization of FLL detected with US in patients with non-cirrhotic liver with a history or clinical suspicion of malignant disease (LoE 2, weak recommendation) (Pro 31, Abs 0 , Against 0).

\section{RECOMMENDATION 12}

CEUS is recommended for the characterization of FLL in the non-cirrhotic liver in patients with inconclusive findings at $\mathrm{CT}$ or MR imaging (LoE 2, strong recommendation) and is suggested if biopsy of the FLL was inconclusive (LoE 5, weak recommendation) (Pro 30, Abs 0, Against 1).

\section{RECOMMENDATION 13}

CEUS is recommended to characterize FLL in the non-cirrhotic liver if both CT and MR imaging are contraindicated (LoE 5, strong recommendation) (Pro 32, Abs 0, Against 0).

For differential diagnosis of FLL, CEUS is superior to CT and equivalent to MR imaging $[30,33,45,64,68]$. CEUS has been shown to be the most cost effective imaging modality in some countries in Europe [80].

\section{Benign solid FLLs}

In addition to contrast enhancement of the FLL compared to the adjacent tissue, vascular architecture during AP can further characterize FLL. The enhancement patterns are summarized in - Table 2.

\section{Hemangioma}

After focal fatty sparing, hemangioma is the second most common benign solid lesion of the liver [61, 81]. In asymptomatic patients with a normal appearing liver on US and without findings or history of malignant or chronic liver disease, a well-circumscribed, round-shaped hyperechoic and homogeneous FLL $<30 \mathrm{~mm}$ without intralesional vessels at color Doppler and without halo sign is diagnostic of hemangioma. CEUS or other contrast-enhanced imaging modalities are not recommended for further characterization [82, 83]. CEUS is indicated when a definitive diagnosis of a hemangioma cannot be achieved using conventional US, as the addition of CEUS markedly improves the diagnostic accuracy in $90-95 \%$ of cases $[29,66,76]$.

The typical CEUS feature of a hemangioma is peripheral, discontinuous nodular (syn.: globular) enhancement in the AP with progressive centripetal partial or complete fill-in [84-87]. Complete fill-in occurs only in $40-50 \%$ cases during the LP. This filling-in is often more rapid in smaller lesions and the entire lesion may be hyperenhancing in the AP. Persistent iso- or hyperen- hancement is sustained through the LP [76, 88-92]. On post-vascular imaging using Sonazoid, hemangiomas appear iso- to hypoenhancing relative to the surrounding liver parenchyma, and may resemble metastatic tumors and HCCs [93, 94]. Overall sensitivity of CEUS for diagnosis of haemangioma is $86 \%$ (95\% $\mathrm{Cl}$ : 81-92\%) according to a meta-analysis including 612 cases from 20 studies [30].

Atypical appearances, in particular LP hypoenhancement (UCA washout) or lack of centripetal fill-in, have been described and may be explained by the destruction of microbubbles that are not adequately replenished due to very long bubble transit times within the lesion [95]. Hemangiomas with arteriovenous shunts (also called high flow or shunt hemangiomas) show rapid homogeneous hyperenhancement in the AP and therefore can be confused with focal nodular hyperplasia (FNH), or even with hepatocellular adenomas (HCA) or HCCs [76]. They are almost always hyperenhancing in the PVP and LP. Thrombosed hemangiomas show lack of enhancement and can be confused with malignancy if only identified during the later CEUS phases [76, 96].

\section{Focal nodular hyperplasia (FNH)}

On CEUS, FNH typically appears as a hyperenhancing homogeneous lesion in all phases. The hyperenhancement might be only mild during the PVP and LP [67, 77, 97-100]. Hyperenhancement is usually marked in the AP [100], with a rapid fill-in from the center outwards (a spoke-wheel pattern) (70\%) or sometimes with an eccentric vascular or multilocular arterial supply $(30 \%)[77,84]$. A centrally hypo- or non-enhancing located scar may be seen in the LP. This, together with the direction of filling of the lesion in the AP if recognizable (centrifugal vs. centripetal), is an important feature to distinguish FNH from shunt (high-flow) hemangiomas. In distinction to an FNH, HCA and a hypervascular malignant FLL show washout as the most important CEUS feature [90].

In the vast majority of cases $(93.5 \%)$ iso- or only slight hyperenhancement of FNH is observed in post-vascular phase compared with the surrounding liver parenchyma, whereas in the remainder $(6.5 \%)$ hypoenhancement is observed [101, 102].

Overall sensitivity of CEUS for diagnosis of $\mathrm{FNH}$ is $88 \%(95 \% \mathrm{Cl}$ : $81-94 \%$ ) according to a large meta-analysis of 365 FNH from 18 studies [30]. Several studies have suggested that diagnostic accuracy of CEUS for diagnosis of FNH is a "matter of size", with accuracy decreasing in patients with lesion size $>30 \mathrm{~mm}[2,3]$.

\section{Hepatocellular adenoma (HCA)}

HCA is a rare benign and sometimes estrogen-dependent hepatic neoplasm. Typical imaging characteristics of HCA are displayed in smaller lesions < $50 \mathrm{~mm}$ [77, 90]. At CEUS, HCA shows homogeneous arterial hyperenhancement, typically with rapid, complete, peripherally dominated filling without a spoke-wheel pattern and without a peripheral globular enhancement pattern, which often enables the correct differential diagnosis, except in telangiectatic and inflammatory HCA [87]. However, HCCs and hyperenhancing metastases may exhibit a similar arterial enhancement pattern, making the differentiation impossible during the AP. In the early PVP, HCA usually become isoenhancing or, more rarely, remain slightly hyperenhancing [77, 97]. Previous bleeding episodes or 
- Table 2 Enhancement patterns of benign focal liver lesions in the non-cirrhotic liver.

\begin{tabular}{|c|c|c|c|c|}
\hline lesion & Arterial phase & portal venous phase & late phase & post-vascular phase \\
\hline \multicolumn{5}{|l|}{ hemangioma } \\
\hline typical features & $\begin{array}{l}\text { peripheral nodular } \\
\text { enhancement }\end{array}$ & $\begin{array}{l}\text { partial/complete } \\
\text { centripetal fill in }\end{array}$ & $\begin{array}{l}\text { Incomplete or complete } \\
\text { enhancement }\end{array}$ & $\begin{array}{l}\text { iso/slightly hypo- } \\
\text { enhancing }\end{array}$ \\
\hline additional features & $\begin{array}{l}\text { small lesion: complete, } \\
\text { rapid centripetal } \\
\text { enhancement }\end{array}$ & & nonenhancing regions & nonenhancing regions \\
\hline \multicolumn{5}{|l|}{ FNH } \\
\hline typical features & $\begin{array}{l}\text { hyperenhancing from the } \\
\text { center, complete, early }\end{array}$ & hyperenhancing & iso/hyperenhancing & $\begin{array}{l}\text { iso/slightly hyper- } \\
\text { or hypoenhancing }\end{array}$ \\
\hline \multirow[t]{2}{*}{ additional features } & spoke-wheel arteries & $\begin{array}{l}\text { unenhanced central } \\
\text { scar }\end{array}$ & $\begin{array}{l}\text { unenhanced central } \\
\text { scar }\end{array}$ & \\
\hline & feeding artery & & & \\
\hline \multicolumn{5}{|c|}{ hepatocellular adenoma } \\
\hline typical features & $\begin{array}{l}\text { hyperenhancing, } \\
\text { complete }\end{array}$ & isoenhancing & isoenhancing & \\
\hline \multirow[t]{2}{*}{ additional features } & nonenhancing regions & hyperenhancing & slightly hypoenhancing & \\
\hline & & nonenhancing regions & nonenhancing regions & \\
\hline \multicolumn{5}{|c|}{ focal fatty infiltration } \\
\hline typical features & isoenhancing & isoenhancing & isoenhancing & isoenhancing \\
\hline \multicolumn{5}{|l|}{ focal fatty sparing } \\
\hline typical features & isoenhancing & isoenhancing & isoenhancing & isoenhancing \\
\hline \multicolumn{5}{|l|}{ abscess } \\
\hline typical features & $\begin{array}{l}\text { peripheral enhancement, } \\
\text { no central enhancement }\end{array}$ & $\begin{array}{l}\text { hyper-/isoenhancing } \\
\text { rim, no central } \\
\text { enhancement }\end{array}$ & $\begin{array}{l}\text { hypoenhancing rim, no } \\
\text { central enhancement }\end{array}$ & hypoenhancing rim \\
\hline \multirow[t]{3}{*}{ additional features } & & hypoenhancing rim & & \\
\hline & enhanced septa & enhanced septa & & \\
\hline & $\begin{array}{l}\text { hyperenhanced liver } \\
\text { segment }\end{array}$ & $\begin{array}{l}\text { hyperenhanced liver } \\
\text { segment }\end{array}$ & & \\
\hline \multicolumn{5}{|l|}{ simple cyst } \\
\hline typical features & nonenhancing & nonenhancing & nonenhancing & nonenhancing \\
\hline
\end{tabular}

necrotic portions exhibit intratumoral nonenhancing areas in larger HCA. In most cases, washout occurs in the LP requiring biopsy to exclude malignancy [90]. Due to the different sub-types of $\mathrm{HCA}$, characterization and differentiation (for example from FNH and HCC such as inflammatory subtype) may be difficult using CEUS as well as MRI and biopsy (HCA $<50 \mathrm{~mm}$ ) or surgery $(\geq 50)$ are indicated for final diagnosis [91]. Liver-specific contrast-enhanced MRI may be helpful when HCA is suspected at CEUS to exclude multilocularity. No studies are available for the diagnosis of HCA using Sonazoid.

\section{Focal fatty change}

Focal fatty changes, either by fat infiltration or fatty sparing are usually shown on conventional B-Mode US as oval or polygonal areas located along the portal bifurcation or close to the hepatic hilum and gallbladder. On visualization of possible focal fat infil- tration, atypical location or history of malignancy should prompt further characterization to exclude malignant lesions. Focal fatty change shows the same degree of enhancement (isoenhancing) as the surrounding liver parenchyma during all phases [92, 103]. Typically, a centrally located artery can be identified [82, 92, 104].

\section{Infection}

The CEUS findings in phlegmonous inflammation are variable. During the early stage of infection, lesions often appear hyperenhancing, while mature lesions develop non-enhancing foci as liquefaction progresses. Mature liver abscesses on CEUS show enhancement of the margins and frequently of the septae in the AP, which sometimes can be followed by PVP hypoenhancement. The most prominent feature on CEUS is the nonenhancement of the liquefied portions combined with arterial rim enhancement [105-109]. Diffuse hyperenhancement of the affected liver sub- 
- Table 3 Enhancement patterns of malignant focal liver lesions in the non-cirrhotic liver.

\begin{tabular}{|c|c|c|c|c|}
\hline tumor & $\begin{array}{l}\text { arterial phase } \\
(10-30 \mathrm{~s})\end{array}$ & $\begin{array}{l}\text { portal venous phase } \\
(20-120 \mathrm{~s})\end{array}$ & $\begin{array}{l}\text { late phase } \\
(120-300 \mathrm{~s})\end{array}$ & $\begin{array}{l}\text { post vascular phase } \\
\text { (>10 min) }\end{array}$ \\
\hline \multicolumn{5}{|l|}{ metastasis } \\
\hline typical features & rim-enhancement & hypoenhancing & hypo/nonenhancing & hypo/nonenhancing \\
\hline \multirow[t]{3}{*}{ additional features } & complete enhancement & nonenhancing regions & nonenhancing regions & nonenhancing regions \\
\hline & hyperenhancement & & & \\
\hline & nonenhancing regions & & & \\
\hline \multicolumn{5}{|l|}{$\mathrm{HCC}$} \\
\hline typical features & hyperenhancing & isoenhancing & hypo/nonenhancing & hypo/nonenhancing \\
\hline additional features & nonenhancing regions & nonenhancing regions & nonenhancing regions & nonenhancing regions \\
\hline \multicolumn{5}{|l|}{ cholangiocarcinoma } \\
\hline \multirow[t]{2}{*}{ typical features } & $\begin{array}{l}\text { rim-like hyperenhance- } \\
\text { ment, }\end{array}$ & hypoenhancing & hypo/nonenhancing & hypo/nonenhancing \\
\hline & central hypoenhancement & & & \\
\hline \multirow[t]{2}{*}{ additional features } & nonenhancing regions & nonenhancing regions & nonenhancing regions & nonenhancing regions \\
\hline & $\begin{array}{l}\text { inhomogeneous } \\
\text { hyperenhancement }\end{array}$ & & & \\
\hline
\end{tabular}

segment(s) in the AP and LP washout of liver parenchyma surrounding the nonenhancing necrotic area have been described in the majority of cases [109].

The appearances of granulomas and focal tuberculosis on CEUS are variable, which make it hard and sometimes impossible to differentiate these from malignancy [107, 110-112].

\section{Other solid benign liver lesions}

A range of other, very rare, solid benign liver lesions can be seen including the following entities:

- Active hemorrhage (including spontaneous, traumatic and iatrogenic liver bleedings) demonstrates contrast extravasation whereas hematomas appear as non-enhancing areas.

- Inflammatory pseudotumor is a rare disease whose definite diagnosis is usually only made at surgery. It may show arterial enhancement and LP hypoenhancement, falsely suggesting malignancy.

- Hepatic angiomyolipoma is a rare benign mesenchymal tumor. It appears homogeneous in most cases and strongly hyperechogenic at baseline US. CEUS shows arterial hyperenhancement $[76,113]$.

- Cholangiocellular adenomas (CCA or bile duct adenoma) are rare lesions that are usually small $(90 \%<1 \mathrm{~cm})$. CEUS may show strong arterial hyperenhancement and early washout in the PVP and LP (they lack portal veins), falsely suggesting malignancy [114, 115].

- Hepatic epithelioid hemangioendothelioma (HEHE) often manifests as multinodular FLL. On CEUS, HEHE shows rim-like or heterogeneous hyperenhancement in the AP and hypoenhancement in the PVP and LP, a sign of malignancy [96, 116, 117]. Some patients show centrally located unenhanced areas.
In contrast, all hemangioma and FNH show hyper- or isoenhancement in the PVP and LP, which is their most distinguishing feature.

For liver trauma we refer to the recently published EFSUMB Guidelines and Recommendations for the Clinical Practice of ContrastEnhanced Ultrasound (CEUS) in Non-Hepatic Applications: Update $2017[4,5]$.

\section{Malignant solid FLLs}

In patients with a non-cirrhotic liver, metastases are more common than primary liver malignant tumors, though conventional US is occasionally helpful to show the malignant nature of an FLL, by demonstrating a hypoechoic halo and infiltration of intrahepatic vessels. Contrast enhanced imaging is necessary to determine the malignant nature under many circumstances, which is true for US, CT and MRI $[45,118]$. Contrast washout in the PVP and LP is the most important feature to determine malignancy $[2,3]$. Almost all metastases show this feature, regardless of the enhancement pattern in the AP. Very few exceptions to this rule have been reported, mainly in liver metastases of neuroendocrine tumors and atypical HCC ( $\triangleright$ Table 3$)$.

\section{Hepatocellular carcinoma in the non-cirrhotic liver}

Hepatocellular carcinoma (HCC) is the most common primary liver malignancy and most of the patients are at risk with known or unknown liver cirrhosis [119]. There is little literature on the value of CEUS in the diagnosis of HCC in the non-cirrhotic liver. Generally, the enhancement patterns of HCC in the non-cirrhotic liver on CEUS are similar to HCC in the cirrhotic liver, but size at time of diagnosis tends to be larger [60]. HCA and FNH are the main dif- 
ferential diagnoses $[90,120]$. HCC in the non-cirrhotic liver are usually hyperenhancing in the AP, typically with a chaotic vascular pattern [121] and variably iso- or hypoenhancing in the PVP and LP [88]. Hyperenhancement in the AP is often homogenous but starts predominantly along the periphery [122]. The fibrolamellar variant of HCC has nonspecific appearances at CEUS. According to expert opinions and case reports, they show rapid wash-in with a heterogeneous pattern in the AP and early PVP and early and marked washout thereafter $[123,124]$.

\section{Cholangiocarcinoma \\ (intrahepatic cholangiocellular carcinoma, ICC)}

ICC is the second most common primary malignant liver tumor and usually arises in healthy liver parenchyma. The different treatment approaches and prognosis, necessitate that ICC is distinguished from HCC [125]. Although rarely observed in Europe and America, more frequently seen in Asia, where combined HCC-ICC also exists [126].

In distinction to the late enhancement on CECT or CEMRI, ICC has a variety of patterns in the AP at CEUS but all show washout in the $\operatorname{LP}[59,113,127]$. The typical pattern of malignancy is better displayed by CEUS than by CECT or CEMRI $[128,129]$.

There is controversy on the differential diagnosis of HCC and ICC with CEUS [35, 52, 93, 130-137]. Compared to HCC, ICC shows a less intense enhancement in the AP and shows early (<60 seconds) and marked washout compared to a typically late and mild washout in HCC [93]. ICC can be subcategorized into three types: mass-forming, periductal infiltrating, and intraductal growing. Mass-forming ICC can exhibit four enhancement patterns in the AP; peripheral irregular rim-like enhancement, heterogeneous hyperenhancement, homogeneous hyperenhancement, and heterogeneous hypoenhancement [113, 127]. Massforming ICC usually shows washout in PVP and invariably shows marked hypoenhancement in the LP followed by complete hypoenhancement in the postvascular phase $[53,138]$.

During the AP, periductal infiltrating ICCs appear heterogeneously enhancing, intraductal growing ICCs exhibit homogeneous hyper-enhancement in most cases. Both lesions show marked washout during PVP and LP [138].

\section{Metastases}

Liver metastases are the most common malignant lesions of liver, arising mainly from cancers of the gastrointestinal tract, breast, pancreas or lung. CEUS markedly improves the detection of liver metastases compared to conventional US. Liver metastases can be detected and characterized reliably as hypoenhancing lesions during the PVP and LP, with few exceptions. Washout is of marked degree and with early onset, usually before 60 sec after UCA injection. In the LP, very small metastases may be conspicuous and lesions that were occult on B-Mode US can be detected [45]. Due to lack of Kupffer cells, metastatic lesions on post-vascular phase imaging with Sonazoid are clearly demarcated and completely hypoenhancing [53, 136, 137, 139-141].

Metastases usually show at least some contrast enhancement in the AP, exhibiting sometimes a marked and chaotic enhancement. Rim or halo enhancement is often seen [2, 3].

\section{Lymphoma}

Lymphoma shows variable arterial enhancement but characteristic fast and marked washout in the PVP and LP, predictive of malignancy $[87,142,143]$.

\section{Focal cystic liver lesions (benign and malignant)}

Focal cystic liver lesions (FCLL) represent a wide spectrum of benign and malignant disease [114]. Benign FCLL include simple cysts, hematoma and hemorrhagic hepatic cysts [144, 145], abscess, bilomas, hydatid cysts [146], cystic cavernous hemangiomas [147] and cystic HCA and other rare entities [86, 148]. Malignant FCLL include cystic HCC [149], cystic lymphoma, cystic metastases as typically seen in neuroendocrine tumors [150] and other rare entities.

Simple cysts are completely non-enhancing on CEUS, and CEUS is not indicated for assessment of simple cysts but useful to evaluate complicated or atypical cysts [145].

With complex cystic masses, CEUS characterizes the vascular flow within septa in cystadenoma and cystadenocarcinoma [1, 151]. Such septa are often visualized by US but not by CT and MRI. Some atypical cystic lesions may have a solid appearance at conventional US, thus mimicking a malignant lesion, particularly a cystic metastasis or biliary cystadenocarcinoma [1, 32].

The CEUS distinguishing feature in the differential diagnosis of hepatic cystadenoma (HBCA) from hepatic cystadenocarcinoma (HBCAC) is the honeycomb septal hyperenhancement during the AP for HBCA, and hypoenhancement during the PVP and LP for HBCAC [1].

\section{RECOMMENDATION 14}

If CEUS has definitively characterized a benign FLL, further investigations are not recommended to confirm the diagnosis (LoE 1, strong recommendation) (Pro 26, Abs 5, Against 0).

\section{RECOMMENDATION 15}

CEUS can be used to characterize hepatic abscess in the appropriate clinical setting (LoE 2, weak recommendation) (Pro 24, Abs 2, Against 1).

\section{CEUS for characterization of FLLs in liver cirrhosis}

\section{Study procedure}

In addition to the general recommendations for the study of FLL, important aspects should be followed if the liver is cirrhotic. Since the AP is crucial to observe for characterization of FLL in cirrhosis, good visualization of the nodule is important. Despite the use of a low MI, microbubbles can be disrupted and acoustic output power should then be reduced, while maintaining sufficient signal intensi- 
ty to allow contrast persistence until the very LP (beyond 3-4 minutes); crucial for detecting washout and establishing a diagnosis of HCC. Furthermore, when the arterial/early PVP is complete (after 60 seconds), it is recommended to image the lesion intermittently (usually brief scan every 30 to 60 seconds), rather than continuously, to minimize microbubble destruction that may cause problems in the identification of subtle or late washout.

\section{Image interpretation and evaluation}

The key feature for the diagnosis of HCC in liver cirrhosis is AP hyperenhancement (APHE), followed by late onset mild washout (>60 sec after injection) [152-156]. This pattern of washout in a HCC is seen in more than $97 \%$ of cases according to a large retrospective series [157]. Arterial hyperenhancement is usually homogeneous and intense in HCC, but may be inhomogeneous in larger nodules $(>5 \mathrm{~cm})$ that are necrotic. Rim enhancement is atypical for HCC. Washout is observed overall in about half the cases of HCC, but rarely in small nodules $(20-30 \%$ in those $1-2 \mathrm{~cm}, 40-60 \%$ in those $2-3 \mathrm{~cm}$ ) [49, 132, 158]. Washout is observed more frequently in HCC with poorer grades of differentiation than in well-differentiated HCC, which tend to be isoenhancing in the LP [159-162]. ICC risk is increased in patients with liver cirrhosis, but only $1-2 \%$ of newly detected FLL in a cirrhotic liver are ICCs [126, 163].

Hypoenhancement in the LP is usually less marked in HCC than in other primary tumors or in liver metastases [159, 164]. Furthermore, the washout tends to start later in HCC, usually not before 60 seconds after injection [159, 164] and appearing only after 180 seconds in up to $25 \%$ of cases [159, 164]; consequently, it is important to observe nodules in cirrhosis until late ( $>4$ minutes). Early washout (<60 seconds) has been reported to occur in poorly differentiated HCC or to suggest a non-hepatocellular malignancy [159, 160, 162, 164], most often a peripheral ICC. For details regarding the CEUS Liver Imaging Reporting and Data System (LI-RADS) classification we refer to the published literature [52, $128,129,133-135,152,156,165,166]$. Sensitivity of CEUS for diagnosis of $\mathrm{HCC}$ is $88 \%$ ( $95 \% \mathrm{Cl}$ : $84-92 \%$ ) according to a metaanalysis including 1333 HCCs from 19 studies [30].

\section{RECOMMENDATION 16}

CEUS can be utilized in first line to characterize FLL found in patients with liver cirrhosis to establish a diagnosis of malignancy (CEUS LR-M) or specifically of HCC (CEUS LR-5), but CT or MR imaging remain required for accurate staging unless contraindicated (LoE2, weak recommendation) (Pro 29, Abs 0, Against 0).

\section{RECOMMENDATION 17}

CEUS can be utilized when CT or MR imaging is inconclusive, especially in FLL in cirrhotic liver not suitable for biopsy, to assess the probability of a lesion to be an HCC (LoE3, weak recommendation) (Pro 29, Abs 0, Against 0).

\section{RECOMMENDATION 18}

CEUS can be utilized for the selection of FLL(s) in a cirrhotic liver to be biopsied when they are multiple or have different contrast patterns (LoE4, weak recommendation) (Pro 28, Abs 1, Against 0).

\section{RECOMMENDATION 19}

CEUS can be used to monitor changes in enhancement patterns in FLL in cirrhotic liver requiring follow-up (LoE4, Weak Recommendation) (Pro 29, Abs 0, Ag 0).

\section{Characterization of portal vein thrombosis}

CEUS is superior to color Doppler US for the diagnosis of portal vein thrombosis [167]. Acute bland thrombus is typically "avascular" and shows as a void within the enhancing liver in all phases of CEUS but best visualized during the PVP. A "tumor in vein" has the same enhancement characteristics as the tumor from which it originated, including rapid AP hyperenhancement and washout [26, 167-173].

Differential diagnosis between partially occlusive/recanalized bland thrombus and "tumor-in-vein" is more challenging. For reliable differentiation, careful assessment of the arrival time of the UCA to the vein is needed. Early arrival of UCA into the lesion in the portal vein at about the same time as opacification of hepatic arteries suggests tumor but this behavior is not specific to HCC. Tumor in peripheral portal veins may be mistaken for tumor nodules, erroneously downstaging the patient. Avoidance is facilitated by real-time imaging while sweeping through the liver, especially in the PVP, to depict the tubular configuration of the tumor and its continuity with more central portal or hepatic veins.

The tumor source of a malignant portal vein thrombus may be obvious, or it may be identified with the assistance of CEUS. A suspicious thrombus within the portal vein may be amenable to US guided biopsy, targeting, if possible, any enhancing regions within the thrombus $[167,169,173,174]$.

\section{RECOMMENDATION 20}

CEUS is recommended to differentiate between benign and malignant portal vein thrombosis (LoE 2, strong recommendation) (Pro 26, Abs 1, Against 0).

\section{Contrast enhanced intraoperative ultrasound (CE-IOUS)}

Several studies using different UCAs have shown that contrast enhanced intraoperative US (CE-IOUS) enhances tumor detection and allows to assess the region for resection, where previously a pre-treatment colorectal liver metastasis was present but has re- 
gressed [175-182]. In particular it has proven valuable for the differential diagnosis between HCC and dysplastic nodule, using both SonoVue [176] and Sonazoid [180]. In addition, CE-IOUS may have an important impact on surgical strategy depending on the attitude of the surgeon [183]. The study procedure and image interpretation of CE-IOUS examination are the same as for the transabdominal approach described in the above sections [175]. The most important difference is that CE-IOUS is performed during the surgical procedure and uses an intraoperative transducer, which, because of its higher frequency, may require a higher UCA dosage.

\section{RECOMMENDATION 21}

CE-IOUS can be used to detect and characterize FLLs not detected at preoperative imaging (LoE 3, strong recommendation) (Pro 27, Abs 0, Against 0).

\section{RECOMMENDATION 22}

CE-IOUS is recommended to assess the region for resection, where previously a pre-treatment colorectal liver metastasis was present but has regressed (LoE 2, strong recommendation) (Pro 27, Abs 0, Against 0).

\section{CEUS for guiding biopsy}

Ultrasound is an established technique to guide biopsy of FLLs, with excellent safety profile and good overall accuracy [184, 185]. Ultrasound is inferior to MR and CT in detecting liver lesions, but with CEUS the sensitivity is comparable to CECT and CEMRI, but importantly, CEUS enables real-time guidance of the biopsy procedure. The addition of CEUS could potentially increase the diagnostic outcome of percutaneous biopsies for four different reasons [186-198]:

- Biopsy can be made from perfused areas to avoid necrosis or avascular tissue [186-192].

- Biopsy can be made of poorly visualized or "invisible" lesions on B-mode US [188-190, 193-198].

- Biopsy can be avoided completely if a CEUS study unequivocally shows typical features of benign FLL or HCC in an appropriate patient population [2, 3].

- The combination of image fusion techniques and CEUS may have a synergistic effect on both modalities. CEUS fusion has been proven to visualize lesions invisible at conventional US fusion in a substantial number of cases $[197,198]$.

\section{Study procedure}

Depending on the contrast agent, a two-step procedure is recommended. Typically, the first UCA dose is injected to characterize the target lesion and select a zone for biopsy; and the second dose used for the CEUS-guided biopsy itself. Dual-screen contrast imaging is recommended with simultaneous contrast imaging on one side to visualize the lesion and conventional B-mode imaging on the other to track the needle. Biopsy should be performed during the contrast phase in which the lesion is best visualized. CEUS prior to a suggested US-guided biopsy of a FLL can help by avoiding biopsy in the case of a diagnostically unequivocal CEUS result. Conventional unenhanced US guidance is adequate for biopsy of most tumors detected on real-time US and there is no rationale for substituting with CEUS-guidance for routine use.

\section{RECOMMENDATION 23}

CEUS-guidance should be attempted to biopsy FLLs that are invisible or inconspicuous at B-mode imaging (LoE 1, strong recommendation) (Pro 27, Abs 2, Against 0).

\section{RECOMMENDATION 24}

CEUS-guidance should be considered in FLLs with potential necrotic areas or if previous biopsy resulted in necrotic material (LoE 4, weak recommendation) (Pro 29, Abs 0, Against 0).

\section{Intracavitary uses}

Intracavitary CEUS (ICCEUS, intracavitary administration of UCAs) is increasingly used as an adjunct to US-guided interventional techniques [199-202]. Concepts and techniques have been published [203-205]. Liver abscess drainage and biliary drainage procedures using ICCEUS have been described in detail. A systematic review covering the role of CEUS in relation to percutaneous intervention has been published [190].

\section{Study procedure}

The standard dosage for intracavitary CEUS is approximately 1 drop UCA per $10 \mathrm{~mL}$ normal saline but may vary with the anticipated distribution volume (e.g. ascites). Higher concentrations are possible for problem solving decisions, but accurate imaging is dependent on correct dilution dosage; high concentrations will result in acoustic shadowing. Higher frequency transducers (linear, endoscopic US) demand higher concentrations.

\section{CEUS guided biliary interventions}

CEUS-guided percutaneous cholangiography can delineate the biliary tree via drainage catheters, T-tubes placed intraoperatively, or during endoscopic access [206-216]. Intraoperatively, $3 \mathrm{D}$-intracavitary CEUS can aid the surgeon to plan resection lines [206-216]. 
Intracavitary CEUS of the biliary tree is used

- during the intervention procedure

- to demonstrate puncture or cannulation success

- to evaluate for communication with other structures, e. g. intestine [214], pleural cavity [206, 207], gall bladder, vessels [210], abscesses or others

- to evaluate the level of obstruction [216]

- after the interventional procedure

- to evaluate for dislodgement or occlusion.

Importantly, intracavitary CEUS reduces or obviates radiation exposure during the intervention. In addition, it has a positive impact on patient logistics during both procedure and follow-up by making transportation of the patient to an X-ray fluoroscopyroom unnecessary when catheter dislodgement is suspected, allowing bedside investigation with a portable US system.

\section{CEUS for the abscess drainage}

Image-guided liver abscess management, normally with US or CT guidance, is a standard procedure, with advantages of both efficiency and effectiveness, allowing percutaneous abscess drainage with either a needle or catheter, with concurrent lavage [184]. During image guided intervention, correct placement of the needle or the drainage catheter can be confirmed using intracavitary CEUS [205]. Communication with other abscess cavities or other structures can be demonstrated or excluded (e.g. bile duct, pancreatic pseudocyst, peritoneal cavity, pleural space), resulting in additional interventions in a number of instances (biliary drainage, pleural drainage, additional abscess interventions in complex cases, pseudocyst intervention etc.). During follow up, the cavity size can be evaluated, and dislodgement of a drainage catheter can be identified or excluded [217, 218].

\section{RECOMMENDATION 25}

ICCEUS can be used for delineation of the liver abscess cavity, identification of correct drain position and of communication with other structures (LoE 3, weak recommendation) (Pro 28, Abs 1, Against 0).

\section{RECOMMENDATION 26}

ICCEUS can be used to guide transhepatic biliary interventions (LoE 3, weak recommendation) (Pro 27, Abs 1, Against 1).

\section{CEUS for interventional tumor ablation}

Ultrasound is the most commonly used imaging modality for guiding ablation therapies in patients with liver tumors [219, 220]. US allows real-time precise placement of the ablation needle in any visualized target lesion. The procedure is safe, rapid and cost-effective in comparison to other imaging modalities, allowing positioning within the target in a short time [184]. The adjunctive use of CEUS is recommended for pre-treatment evaluation of the ablation target, and also for peri-procedural assessment of treatment results $[184,190]$. CEUS-guided ablation of liver tumors may be dispensed with when the lesion target is well recognizable at conventional B-mode US.

\section{Pre-treatment CEUS}

Pre-treatment evaluation includes assessment of ablation target size, vascularization and tumor margins. For ablative treatment of undetected or inconspicuous target lesions at unenhanced US, availability of CEUS-guided technology and possibly real-time CEUS fusion imaging is of pivotal importance [196, 221-224]. Often, two intravenous injections are required: the first to identify the target lesion and plan treatment, the second for correct positioning of the ablation needle. For CEUS, dual screen is recommended to allow the simultaneous real-time visualization of the probe insertion with both conventional B-mode US and CEUS.

\section{RECOMMENDATION 27}

CEUS prior to US guided ablation procedure is recommended as a complement to US, CT and MRI for treatment planning (LoE 2, strong recommendation) (Pro 27, Abs 2, Against 0).

\section{RECOMMENDATION 28}

CEUS-guidance is recommended for the US guided ablation of tumors that are invisible or inconspicuous on US (LoE 2, strong recommendation) (Pro 27, Abs 2, Against 0).

CEUS performed 10-15 minutes after ablation treatment should be considered for immediate evaluation of therapeutic efficacy and for early detection of residual viable tumor, which allows for instantaneous CEUS-guided re-ablation under the same anesthesia. This technique has been proven to decrease both the number of second ablation sessions and the tumor recurrence rate during follow-up [225-227]. Similarly, CEUS fusion imaging with CT/MR imaging for periprocedural assessment of ablation has been reported to enable immediate repeat ablations under CEUS or CEUS-CT/MR fusion imaging-guidance, and decrease long term local tumor progression [228-232].

\section{Study procedure}

After cessation of ablation, a 5-10 minutes period is necessary before performing CEUS to allow the hyperechoic "cloud" of gas produced during the ablation to diffuse into tissue. In cases of residual tumor, a second CEUS injection must be used to allow correct insertion of the ablation needle. 


\section{RECOMMENDATION 29}

CEUS is recommended for the evaluation of the treatment effect after ablation and guidance for immediate US guided retreatment of residual tumor (LoE 2, strong recommendation) (Pro 26, Abs 0, Against 2).

\section{Post-treatment CEUS}

CEUS is a reliable method for evaluation of the ablation margin and detection of tumor recurrence, potentially reducing the number of CT examinations needed during follow-up [225, 229, 232239].

\section{Follow-up CEUS}

The purpose of first post-ablation CEUS is to evaluate immediate treatment response of the target lesion (by size, perfusion, safety margin and residual viable tumor) and to look for complications (such as hemorrhage, hepatic infarction, bile duct dilatation, abscess, biliary tumor, etc.) [226, 240]. Regular CEUS follow-up weeks to months after ablation can detect local recurrence and new lesions [190, 221, 222, 224, 239]. Frequently, more than one injection is required to evaluate multi-ablated lesions, any suspicious areas or new lesions.

\section{RECOMMENDATION 30}

CEUS is recommended as the priority imaging method in the follow-up after ablation treatment to identify residual or recurrent tumor at appropriate time intervals (LoE 2, strong recommendation) (Pro 24, Abs 3, Ag 0).

In the early post-ablation evaluation (within the first 30 days), a thin, uniform enhancing hyperemic rim is visible along the periphery of the necrotic region, similar to the findings on CECT. Due attention must be taken not to confuse this with recurrence.

\section{Monitoring Medical Tumor treatment} response

Neoangiogenesis is an important target for novel anticancer treatments and many new antiangiogenesis or antivascular treatments aim at destroying or limiting the growth of tumor vessels [241, 242]. Dynamic contrast enhanced US (DCEUS) has emerged for monitoring the response to these drugs [243]. Initially, such monitoring relied on qualitative analyses only. More recently, robust and quantitative features have been developed. To achieve successful results, standardization and strict control of scanner settings are needed [243].

\section{Methodology and equipment for quantification}

Measurements of contrast kinetics are performed using a time-intensity curve (TIC) analysis of dynamic contrast enhancement.
Background subtraction is necessary to compensate for attenuation effects [244] and extract reliable time-based features, such as time to peak, mean transit time, etc. However, the nonlinear compression applied to the original signals (required to display them on video monitors) distorts amplitude-based TIC features (e. g., peak intensity and area under the curve) [245]. The majority of reports have used uncompressed, post beamformed data (radio-frequency data are not required since the phase information is not essential). TIC based on such raw data sets allow for accurate assessment of both time-based and amplitude-dependent features. All manufacturers that supply built-in analysis packages on their scanners use this type of data but off-line software packages are also available [246]. For details of administration of UCA and quantitative analysis we refer to the EFSUMB position paper [243].

\section{Assessment of antiangiogenic treatment}

Since antiangiogenic treatments frequently induce necrosis without causing tumor shrinkage, functional imaging techniques are particularly suitable for the early assessment of response, a task for which both the RECIST and World Health Organization (WHO) size criteria [247, 248] are unsatisfactory. Studies of various types of tumors such as HCC, gastrointestinal stromal tumor (GIST) or renal cell carcinoma (RCC) treated with antiangiogenic therapies have confirmed that DCEUS may allow early prediction of response to treatment [91, 96, 249-262]. The first multicenter study including more than 500 patients in 19 centers [263] correlated DCEUS with progression free survival (PFS) and overall survival (OS). A decrease of $40 \%$ of AUC at one month was correlated to PFS and OS in patients treated with thyrosine kinase inhibitors [264].

\section{RECOMMENDATION 31}

DCE-US can be used in the quantitative assessment of response to targeted therapies in patients with malignant tumors of the liver (LoE 2, weak recommendation) (Pro 22, Abs 5, Against 0).

\section{Paediatric liver lesions}

Ultrasound imaging is the ideal imaging technique for many areas in pediatrics, and should always be the first line imaging modality whenever practicable [19]. The advantages of US are established: it is child-friendly, easy to use in the difficult child, repeatable, and has limited safety issues. Moreover, in liver imaging, the relatively fat free body habitus of the child renders US an ideal technique for assessment of FLLS. CEUS in the assessment of pediatric liver lesions has been investigated by a number of groups, predominantly in Europe and almost exclusively using the agent SonoVue, with some reports from North America using Definity, using these agents off-label in children. There has been approval from the FDA to use Lumason in the assessment of FLLs in children. This is likely to increase the use of CEUS as a first line imaging method for 
the incidental FLL, as well as for the assessment of malignancy, recurrence and treatment response in the pediatric population [265].

Experience with the assessment of pediatric FLL has been based on the extensive investigations of adult FLL, with initial experience using SonoVue in pediatric practice mainly centered around the investigation of indeterminate FLLs seen on an US examination [265]. A single study applying adult criteria for the CEUS diagnosis of FNH and HCA found good concordance with MR and CT imaging [266]. More extensive experience has been documented with blunt abdominal trauma of the liver, and in the follow-up of focal areas of injury in the liver [267-269]. Experience using CEUS in the assessment of the liver transplant recipients is limited, with studies reporting success mainly with areas of infarction and abscess formation, with vascular "Doppler rescue" useful [270-272]. For details we refer to the EFSUMB position paper "Role of Contrast-Enhanced Ultrasound (CEUS) in Paediatric Practice: An EFSUMB Position Statement" [19].

\section{Safety and Dose}

Most extensive assessment of safety in children has been with SonoVue, with reports of severe anaphylaxis in $1 / 137$ (0.6\%) patients studied [273] and two minor delayed adverse reactions in $2 / 305(0.7 \%)$ patients in a review of local clinical practice [274]. Current evidence suggests that the safety profile of using SonoVue in children is similar to that in adults.

The recommended dose from the FDA for Lumason in assessing FLL is based on body weight, $0.03 \mathrm{~mL}$ per $\mathrm{kg}$, not exceeding $2.4 \mathrm{~mL}$ per injection. On a more practical basis, other authors have indicated a dose regime for the liver that is age based, with adult doses for children over 12 years of age (SonoVue $2.4 \mathrm{~mL}$ ), half the adult dose between 6 and 12 years $(1.2 \mathrm{~mL})$, and one quarter the adult dose under the age of six years $(0.6 \mathrm{~mL})$, well within the safety margins of dose finding studies in adults [274]. These relatively small doses may continue to decrease as imaging technology improves [19].

\section{Indications for pediatric liver CEUS}

- The child with any incidentally discovered FLLs on an US examination should also have the opportunity to be assessed with a CEUS examination. The CEUS examination requires an intravenous line, as would a CECT or CEMRI examination. Limited evidence suggests the CEUS assessment of a FLL is as accurate in the child as in the adult, without the morbidity of ionizing radiation, iodinated contrast, gadolinium-based contrast or the need for sedation or general anesthesia.

- Any indeterminate FLL in a child with underlying chronic liver disease from any cause on a follow up program should have a CEUS examination prior to any other imaging, with the possibility of avoiding further imaging if the lesion is categorically benign.

- The assessment of vascular complications following liver transplantation benefits from the 'Doppler rescue' of a CEUS examination before resorting to a CT examination.

- Initial investigation of blunt abdominal trauma in children should involve a CT examination except for the most trivial trauma. Follow-up of the identified areas of localized, low-energy liver trauma may be readily assessed with a CEUS examination, where a complicating traumatic pseudoaneurysm is readily identified, and progressive healing of lacerations or hematomas can be recorded on serial investigations.

\section{RECOMMENDATION 32}

CEUS assessment of FLLs in children is consistent with findings in the adult patients and it should be used to characterize these lesions (LoE 2b, strong recommendation) (Pro 25, Abs 0, Against 0).

\section{RECOMMENDATION 33}

CEUS follow-up of traumatic liver injuries in children should be utilized for the assessment of complications, reducing ionizing radiation exposure (LoE 2, strong recommendation) (Pro 26, Abs 1, Against 0).

\section{Documentation}

All US examinations should principally be documented both by wording and by image storage to ensure high-quality patient care [275]. However, there exists little scientific evidence to substantiate how this should be done. This is a matter of expert opinion and practice differs substantially worldwide. Each image lesion should be described in terms of size, localization (liver segment), and contrast enhancement in all phases [276]. The operator should record the temporal behavior and degree of enhancement relative to surrounding tissue (non-enhanced, hypoenhanced, iso-enhanced or hyper-enhanced), as well as the UCA distribution (homogeneous or heterogeneous) [23].

The written report must include type and dose of UCA applied. Furthermore, the enhancement pattern in all phases should be described with a conclusion regarding diagnosis and follow-up. It is important to report washout timing in actual seconds or minutes. Real-time video clips should be recorded, preferably digitally, in a format which enables later retrieval and comparison [277]. The clips should ideally show the whole examination, but at least the AP and other clinically relevant parts of the scan should be recorded and stored. Cine loops can be supplied with still images of relevant findings. Finally, the clips and images should be archived permanently.

\section{RECOMMENDATION 34}

The user of a CEUS examination should report the type and dose(s) of contrast agent, the enhancement pattern and clinically relevant findings in a written format (LoE 5, strong recommendation) (Pro 27, Abs 1, Against 0). 


\section{RECOMMENDATION 35}

During the CEUS examination representative images and cine loops should be captured and stored according to the relevant medical-legal framework (LoE 5, strong recommendation) (Pro 26, Abs 0, Against 2).

\section{Clinical training and education}

Adequate knowledge and hands-on training are prerequisites for building competence in the use of CEUS. Therefore, it is of great importance to maintain high quality education and high professional standards in the practice of CEUS. In 2006, three levels of training requirements were defined by EFSUMB [261], with Appendix 14 specifically addressing the use of CEUS [262]. It is recommended that CEUS should be performed by operators who have obtained adequate expertise with both conventional US and CEUS. They should be familiar with these techniques and the distribution of pathologies within their local medical environment; they should be recognized as competent by local standards and the relevant medicolegal framework. Some federations offer dedicated CEUS courses on a regular basis, often in collaboration with the UCA- or US-equipment industry and it is beneficial for any user of CEUS to attend such educational activities [278]. It is advised that investigators intending to start using CEUS attend relevant courses and spend time under the supervision of an expert. Ideally, their own department should have sufficient volume of examinations to maintain adequate numbers of cases with various pathologies. Furthermore, it is advised that the manufacturers are consulted to maintain up-to-date CEUS scanner software. The practice of CEUS also requires knowledge of UCA administration, of contra-indications and necessary skills to handle possible side effects within the medico-legal framework of the country of practice.

\section{RECOMMENDATION 36}

Users must have adequate knowledge and training in CEUS, UCA administration and contraindications, and perform the examination within the relevant medico-legal framework (LoE 5, strong recommendation) (Pro 27, Abs 1; Against 0).

\section{Errors and artifacts in CEUS of the liver}

Errors may occur in the CEUS of the liver due to the limitations of CEUS and other factors, such as contrast dose, MI, image artifacts, background noise, pseudoenhancement, unintended microbubble destruction, attenuation, shadowing, prolonged heterogeneous liver enhancement. These errors may result in lesion mischaracterization. It is recommended that CEUS imaging interpretation should be performed in conjunction with analysis of patient's clinical history, symptoms and laboratory values. In select cases when CEUS imaging results are discordant, correlation with other imaging modalities or tissue sampling might be advised.

\section{RECOMMENDATION 37}

Appropriate dose of contrast agent based on lesion location, patient factors and sensitivity of US scanner as well as imaging with appropriate low mechanical index should be used to produce high quality CEUS images (LoE 5, strong recommendation) (Pro 26, Abs 2, Against 0).

Similar to every other imaging modality, image artifacts are often encountered in liver CEUS [279-281]. They may be intrinsic to contrast-mode imaging itself or relate to traditional B-mode artifacts. Some artifacts may affect image quality or simulate pathology but rarely result in misdiagnosis [282]. Others may be useful, leading to more confident diagnosis.

\section{RECOMMENDATION 38}

When using CEUS a knowledge of artifacts associated with CEUS is recommended (LoE 5, strong recommendation) (Pro 27, Abs 1, Ag 0).

\section{Conflict of Interest}

Christoph F Dietrich: Speaker honoraria, Bracco, Hitachi, GE, Mindray, Supersonic, Pentax, Olympus, Fuji, Boston Scientific, AbbVie, Falk Foundation, Novartis, Roche; Advisory Board Member, Hitachi, Mindray, Siemens; Research grant, GE, Mindray, SuperSonic

Richard G Barr: Speaker honoraria, Bracco, Hitachi, GE, Mindray, Supersonic, Philips, Siemens, Lantheus, Canon; Advisory Board - Lanteus and Bracco Diagnostics; Board Member - ICUS; Research Grants Siemens Ultrasound, Philips Ultrasound, GE Ultrasound, GE Medical, Mindray, SuperSonic Imagine, B and K Ultrasound

Annalisa Berzigotti: Research grant, Bracco

Byung Ihn Choi: Speaker honoraria, Samsung

Dirk André Clevert: Speaker honoraria, Bracco, GE, Samsung, Philips, Siemens, Falk Foundation

Jean-Michel Correas: Speaker Honoraria, Canon MS, Hitachi MS, Philips US, SuperSonic Imagine, Novartis, Johnson \& Johnson; Speaker honoraria, Bracco SA: Principal investigator of BR1-127 et SonoCap studies; Speaker honoraria, Guerbet SA: Principal investigator of NsSafe and Secure studies

Odd Helge Gilja: Speaker honoraria, GE Healthcare, Takeda AS; Advisory Consulting, GE, Takeda and Samsung

Vito Cantisani: Speaker honoraria, Samsung, Bracco, Canon J. Brian Fowlkes: Research grants, Philips Healthcare, GE Healthcare; Stock Ownership, Histosonics

Adrian Lim: Advisory Board, Canon Medical Systems, Carestream; Research grant - Philips Medical Systems; Speaker honoraria - Canon, Bracco

Maria Franca Meloni: Speaker honoraria, Bracco

Christian Jenssen: Speaker honoraia, Hitachi, Bracco, Falk Foundation; Expert witness, Hitachi

Mirko D’Onofrio: Speaker honoraria, Bracco, Siemens; Advisory Board, Bracco, Siemens, Hitachi; Research grant, Hitach; Congress Support, Bracco, Siemens

Fabio Piscaglia: Speaker honoraria, Bracco, Bayer, EISAI, Guerbet; Advisory board honoraria: Bayer, EISAI; Research Contract: ESAOTE 
Masatoshi Kudo: Speaker honoraria, Bayer, Eisai, MSD, Ajinomoto; Research Grants, Chugai, Otsuka, Takeda, Taiho, Sumitomo Dainippon, Daiichi Sankyo, MSD, Eisai, Bayer, Abbvie, Medico's Hirata, Astellas Pharma, Bristol-Myers Squibb; Advisory Consulting, Kowa, MSD, BMS, Bayer, Chugai, Taiho, Eisai, Ono pharmaceutical

Yi Dong: Speaker honoraria, Bracco, Siemens

Yuko Kono: Equipment support Canon, GE; Contast agent support Lantheus, Bracco

Andrej Lyshchik: Speaker honoraria, GE Healthcare, Siemens, Canon; Advisory Board, Bracco Diagnostics; Consulting, GE Healthcare; Speaker panel, GE Healthcare, SonoScape; Royalties, Elsevier

Zheng Rongqin: Speaker honoraria, Bracco, Esaote; Research grant, Philips; Congress support, Bracco

Paul Sidhu: Speaker honoraria, Bracco, Siemens, Hitachi, GE healthcare, Philips, Samsung, Advisory Board ITREAS Ltd

The following have declared no conflict of interest:

Peter Burns, Cristina Chammas, Nitin G Chaubal, Pintong Huang,

Andre Ignee, Nathalie Lassau, Jae-Young Lee, Yasunori Minami,

Carlos Nicolau, Christian Nolsoe, Xin-Wu Cui, Adrian Saftoiu,

Guido Torzilli, Ping Liang, Fuminori Moriyasu, Xiaoyan Xie

\section{Acknowledgements}

The authors thank the WFUMB administrator, Lynne Rudd, for her excellent support of the guidelines process. Funds to cover economy travel, accommodations, and a full day meeting for each author in Grenada, Spain in May 2019 were provided by the following companies: BK Medical, Bracco, Esaote, GE Healthcare, Hitachi, Lantheus Medical Imaging, Mindray, Philips, Canon, Samsung, Siemens Healthineers, and Hologic Supersonic Imagine. Representatives from some of the companies were present at the consensus meeting to assist with product technical information but did not take part in forming the recommendations or writing the manuscript. We thank each company for making this consensus meeting possible.

\section{References}

[1] Albrecht T, Blomley M, Bolondi L et al. Guidelines for the use of contrast agents in ultrasound. January 2004. Ultraschall in Med 2004; 25: 249-256

[2] Claudon M, Dietrich CF, Choi BI et al. Guidelines and Good Clinical Practice Recommendations for Contrast Enhanced Ultrasound (CEUS) in the Liver - Update 2012. Ultraschall in Med 2013; 34: 11-29

[3] Claudon M, Dietrich CF, Choi BI et al. Guidelines and good clinical practice recommendations for Contrast Enhanced Ultrasound (CEUS) in the liver update 2012: A WFUMB-EFSUMB initiative in cooperation with representatives of AFSUMB, AIUM, ASUM, FLAUS and ICUS. Ultrasound Med Biol 2013; 39: 187-210

[4] Sidhu PS, Cantisani V, Dietrich CF et al. The EFSUMB Guidelines and Recommendations for the Clinical Practice of Contrast-Enhanced Ultrasound (CEUS) in Non-Hepatic Applications: Update 2017 (Short Version). Ultraschall in Med 2018; 39: 154-180

[5] Sidhu PS, Cantisani V, Dietrich CF et al. The EFSUMB Guidelines and Recommendations for the Clinical Practice of Contrast-Enhanced Ultrasound (CEUS) in Non-Hepatic Applications: Update 2017 (Long Version). Ultraschall in Med 2018; 39: e2-e44

[6] Jenssen C, Gilja OH, Serra AL et al. European Federation of Societies for Ultrasound in Medicine and Biology (EFSUMB) Policy Document Development Strategy - Clinical Practice Guidelines, Position Statements and Technological Reviews. Ultrasound Int Open 2019; 5: E2-E10

[7] Piscaglia F, Bolondi L. The safety of Sonovue in abdominal applications: retrospective analysis of 23188 investigations. Ultrasound Med Biol 2006; 32: $1369-1375$

[8] Main ML, Goldman JH, Grayburn PA. Thinking outside the "box"-the ultrasound contrast controversy. J Am Coll Cardiol 2007; 50: 2434-2437
[9] Main ML, Goldman JH, Grayburn PA. Ultrasound contrast agents: balancing safety versus efficacy. Expert Opin Drug Saf 2009; 8: 49-56

[10] Dietrich CF, Bamber J, Berzigotti A et al. EFSUMB Guidelines and Recommendations on the Clinical Use of Liver Ultrasound Elastography, Update 2017 (Short Version). Ultraschall in Med 2017; 38: 377-394

[11] Tang C, Fang K, Guo Y et al. Safety of Sulfur Hexafluoride Microbubbles in Sonography of Abdominal and Superficial Organs: Retrospective Analysis of 30222 Cases. J Ultrasound Med 2017; 36: 531-538

[12] Kitzman DW, Goldman ME, Gillam LD et al. Efficacy and safety of the novel ultrasound contrast agent perflutren (definity) in patients with suboptimal baseline left ventricular echocardiographic images. Am J Cardiol 2000; 86: 669-674

[13] Wilson SR, Burns PN. Microbubble-enhanced US in body imaging: what role? Radiology 2010; 257: 24-39

[14] Cochran ST, Bomyea K, Sayre JW. Trends in adverse events after IV administration of contrast media. Am J Roentgenol 2001; 176: 1385-1388

[15] Hunt CH, Hartman RP, Hesley GK. Frequency and severity of adverse effects of iodinated and gadolinium contrast materials: retrospective review of 456930 doses. Am J Roentgenol 2009; 193: 1124-1127

[16] CHMP. Committee for Medicinal Products for Human Use (CHMP) Assessment report EMA/84084/2014. SonoVue. international nonproperietary name: sulfur hexafluoride. 2014

[17] Darge K, Papadopoulou F, Ntoulia A et al. Safety of contrast-enhanced ultrasound in children for non-cardiac applications: a review by the Society for Pediatric Radiology (SPR) and the International Contrast Ultrasound Society (ICUS). Pediatr Radiol 2013; 43: 1063-1073

[18] Papadopoulou F, Ntoulia A, Siomou E et al. Contrast-enhanced voiding urosonography with intravesical administration of a second-generation ultrasound contrast agent for diagnosis of vesicoureteral reflux: prospective evaluation of contrast safety in 1010 children. Pediatr Radiol 2014; 44: 719-728

[19] Sidhu PS, Cantisani V, Deganello A et al. Role of Contrast-Enhanced Ultrasound (CEUS) in Paediatric Practice: An EFSUMB Position Statement. Ultraschall in Med 2017; 38: 33-43

[20] Sidhu PS, Cantisani V, Deganello A et al. Authors' Reply to Letter: Role of Contrast-Enhanced Ultrasound (CEUS) in Paediatric Practice: An EFSUMB Position Statement. Ultraschall in Med 2017; 38: 447-448

[21] Sellars ME, Deganello A, Sidhu PS. Paediatric contrast-enhanced ultrasound (CEUS): a technique that requires co-operation for rapid implementation into clinical practice. Ultraschall in Med 2014; 35: 203-206

[22] Schwarze V, Marschner C, Negrao de Figueiredo G et al. Single-Center Study: Evaluating the Diagnostic Performance and Safety of ContrastEnhanced Ultrasound (CEUS) in Pregnant Women to Assess Hepatic Lesions. Ultraschall in Med 2020; 41: 29-35

[23] Dietrich CF, Averkiou M, Nielsen MB et al. How to perform Contrast-Enhanced Ultrasound (CEUS). Ultrasound Int Open 2018; 4: E2-E15

[24] Wilson SR, Kim TK, Jang H] et al. Enhancement patterns of focal liver masses: discordance between contrast-enhanced sonography and contrast-enhanced CT and MRI. Am J Roentgenol 2007; 189: W7-W12

[25] D'Onofrio M, Crosara S, De Robertis R et al. Contrast-Enhanced Ultrasound of Focal Liver Lesions. Am J Roentgenol 2015; 205: W56-W66

[26] Rossi S, Ghittoni G, Ravetta V et al. Contrast-enhanced ultrasonography and spiral computed tomography in the detection and characterization of portal vein thrombosis complicating hepatocellular carcinoma. Eur Radiol 2008; 18: 1749-1756

[27] Faccioli N, D'Onofrio M, Comai A et al. Contrast-enhanced ultrasonography in the characterization of benign focal liver lesions: activitybased cost analysis. Radiol Med 2007; 112: 810-820

[28] Quaia E, Calliada F, Bertolotto M et al. Comparison of diagnostic performance of unenhanced vs SonoVue - enhanced ultrasonography in focal liver lesions characterization. The experience of three Italian centers. Radiol Med (Torino) 2004; 108: 71-81 
[29] Trillaud H, Bruel JM, Valette P] et al. Characterization of focal liver lesions with SonoVue-enhanced sonography: international multicenter-study in comparison to CT and MRI. World J Gastroenterol 2009; 15: 3748-3756

[30] Friedrich-Rust M, Klopffleisch T, Nierhoff J et al. Contrast-Enhanced Ultrasound for the differentiation of benign and malignant focal liver lesions: a meta-analysis. Liver Int 2013; 33: 739-755

[31] D’Onofrio M, Crosara S, De Robertis R et al. Malignant focal liver lesions at contrast-enhanced ultrasonography and magnetic resonance with hepatospecific contrast agent. Ultrasound 2014; 22: 91-98

[32] Barr RG. Contrast enhanced ultrasound for focal liver lesions: how accurate is it? Abdom Radiol (NY) 2018; 43: 1128-1133

[33] Seitz K, Strobel D, Bernatik T et al. Contrast-Enhanced Ultrasound (CEUS) for the characterization of focal liver lesions - prospective comparison in clinical practice: CEUS vs. CT (DEGUM multicenter trial). Parts of this manuscript were presented at the Ultrasound Dreilandertreffen 2008, Davos. Ultraschall in Med 2009; 30: 383-389

[34] Burns PN, Wilson SR. Focal liver masses: enhancement patterns on contrast-enhanced images-concordance of US scans with CT scans and MR images. Radiology 2007; 242: 162-174

[35] Laghi F, Catalano O, Maresca M et al. Indeterminate, subcentimetric focal liver lesions in cancer patients: additional role of contrast-enhanced ultrasound. Ultraschall in Med 2010; 31: 283-288

[36] Parsai A, Miquel ME, Jan $\mathrm{H}$ et al. Improving liver lesion characterisation using retrospective fusion of FDG PET/CT and MRI. Clin Imaging 2019; 55: $23-28$

[37] Jo PC, Jang HJ, Burns PN et al. Integration of Contrast-enhanced US into a Multimodality Approach to Imaging of Nodules in a Cirrhotic Liver: How I Do It. Radiology 2017; 282: 317-331

[38] Itabashi T, Sasaki A, Otsuka K et al. Potential value of sonazoid-enhanced intraoperative laparoscopic ultrasonography for liver assessment during laparoscopy-assisted colectomy. Surg Today 2014; 44: 696-701

[39] Muhi A, Ichikawa T, Motosugi U et al. Diagnosis of colorectal hepatic metastases: comparison of contrast-enhanced $\mathrm{CT}$, contrast-enhanced US, superparamagnetic iron oxide-enhanced MRI, and gadoxetic acidenhanced MRI. J Magn Reson Imaging 2011; 34: 326-335

[40] Cantisani V, Ricci P, Erturk M et al. Detection of hepatic metastases from colorectal cancer: prospective evaluation of gray scale US versus SonoVue(R) low mechanical index real time-enhanced US as compared with multidetector-CT or Gd-BOPTA-MRI. Ultraschall in Med 2010; 31: 500505

[41] Larsen LP, Rosenkilde M, Christensen $\mathrm{H}$ et al. Can contrast-enhanced ultrasonography replace multidetector-computed tomography in the detection of liver metastases from colorectal cancer? Eur ] Radiol 2009; 69: 308-313

[42] Piscaglia F, Corradi F, Mancini M et al. Real time contrast enhanced ultrasonography in detection of liver metastases from gastrointestinal cancer. BMC Cancer 2007; 7: 171

[43] Konopke R, Kersting S, Bergert $\mathrm{H}$ et al. Contrast-enhanced ultrasonography to detect liver metastases: A prospective trial to compare transcutaneous unenhanced and contrast-enhanced ultrasonography in patients undergoing laparotomy. Int J Colorectal Dis 2007; 22: 201-207

[44] Larsen LP, Rosenkilde M, Christensen $\mathrm{H}$ et al. The value of contrast enhanced ultrasonography in detection of liver metastases from colorectal cancer: a prospective double-blinded study. Eur J Radiol 2007; 62: 302307

[45] Dietrich CF, Kratzer W, Strobe D et al. Assessment of metastatic liver disease in patients with primary extrahepatic tumors by contrast-enhanced sonography versus CT and MRI. World J Gastroenterol 2006; 12: $1699-1705$

[46] Konopke R, Kersting S, Saeger HD et al. Detection of liver lesions by contrast-enhanced ultrasound - comparison to intraoperative findings. Ultraschall in Med 2005; 26: 107-113
[47] Quaia E, D'Onofrio M, Palumbo A et al. Comparison of contrast-enhanced ultrasonography versus baseline ultrasound and contrast-enhanced computed tomography in metastatic disease of the liver: diagnostic performance and confidence. Eur Radiol 2006; 16: 1599-1609

[48] Larsen LP. Role of contrast enhanced ultrasonography in the assessment of hepatic metastases: A review. World J Hepatol 2010; 2: 8-15

[49] Forner A, Vilana R, Ayuso C et al. Diagnosis of hepatic nodules $20 \mathrm{~mm}$ or smaller in cirrhosis: Prospective validation of the noninvasive diagnostic criteria for hepatocellular carcinoma. Hepatology 2008; 47: 97-104

[50] Dong Y, Zhang XL, Mao F et al. Contrast-enhanced ultrasound features of histologically proven small $(</=20 \mathrm{~mm})$ liver metastases. Scand J Gastroenterol 2017; 52: 23-28

[51] Tang A, Bashir MR, Corwin MT et al. Evidence Supporting LI-RADS Major Features for CT- and MR Imaging-based Diagnosis of Hepatocellular Carcinoma: A Systematic Review. Radiology 2018; 286: 29-48

[52] Wilson SR, Lyshchik A, Piscaglia F et al. CEUS LI-RADS: algorithm, implementation, and key differences from CT/MRI. Abdom Radiol (NY) 2018; 43: $127-142$

[53] Hatanaka K, Kudo M, Minami Y et al. Sonazoid-enhanced ultrasonography for diagnosis of hepatic malignancies: comparison with contrastenhanced CT. Oncology 2008; 75 (Suppl. 1): 42-47

[54] Moriyasu F, Itoh K. Efficacy of perflubutane microbubble-enhanced ultrasound in the characterization and detection of focal liver lesions: phase 3 multicenter clinical trial. Am J Roentgenol 2009; 193: 86-95

[55] Maruyama H, Takahashi M, Ishibashi $\mathrm{H}$ et al. Ultrasound-guided treatments under low acoustic power contrast harmonic imaging for hepatocellular carcinomas undetected by B-mode ultrasonography. Liver Int 2009; 29: 708-714

[56] Martie A, Bota S, Sporea I et al. The contribution of contrast enhanced ultrasound for the characterization of benign liver lesions in clinical practice - a monocentric experience. Med Ultrason 2012; 14: 283-287

[57] Guang Y, Xie L, Ding $H$ et al. Diagnosis value of focal liver lesions with SonoVue(R)-enhanced ultrasound compared with contrast-enhanced computed tomography and contrast-enhanced MRI: a meta-analysis. J Cancer Res Clin Oncol 2011; 137: 1595-1605

[58] Karhunen PJ. Benign hepatic tumours and tumour like conditions in men. J Clin Pathol 1986; 39: 183-188

[59] Xu HX, Lu MD, Liu G] et al. Imaging of peripheral cholangiocarcinoma with low-mechanical index contrast-enhanced sonography and SonoVue: initial experience. J Ultrasound Med 2006; 25: 23-33

[60] Linhart P, Bonhof JA, Baque PE et al. Ultrasound in diagnosis of benign and malignant liver tumors. Zentralbl Chir 1998; 123: 119-123

[61] Hirche TO, Russler J, Schroder O et al. The value of routinely performed ultrasonography in patients with Crohn disease. Scand J Gastroenterol 2002; 37: 1178-1183

[62] Sandrose SW, Karstrup S, Gerke O et al. Contrast Enhanced Ultrasound in CT-undetermined Focal Liver Lesions. Ultrasound Int Open 2016; 2: E129-E135

[63] Volk M, Strotzer M, Lenhart M et al. Frequency of benign hepatic lesions incidentally detected with contrast-enhanced thin-section portal venous phase spiral CT. Acta Radiol 2001; 42: 172-175

[64] Seitz K, Bernatik T, Strobel D et al. Contrast-enhanced ultrasound (CEUS) for the characterization of focal liver lesions in clinical practice (DEGUM Multicenter Trial): CEUS vs. MRI-a prospective comparison in 269 patients. Ultraschall in Med 2010; 31: 492-499

[65] von Herbay A, Westendorff J, Gregor M. Contrast-enhanced ultrasound with SonoVue: differentiation between benign and malignant focal liver lesions in 317 patients. J Clin Ultrasound 2010; 38: 1-9

[66] Strobel D, Seitz K, Blank W et al. Contrast-enhanced ultrasound for the characterization of focal liver lesions - diagnostic accuracy in clinical practice (DEGUM multicenter trial). Ultraschall in Med 2008; 29: 499505 
[67] Strobel D, Seitz K, Blank W et al. Tumor-Specific Vascularization Pattern of Liver Metastasis, Hepatocellular Carcinoma, Hemangioma and Focal Nodular Hyperplasia in the Differential Diagnosis of 1349 Liver Lesions in Contrast-Enhanced Ultrasound (CEUS). Ultraschall in Med 2009; 30: 376-382

[68] Seitz K, Greis C, Schuler A et al. Frequency of tumor entities among liver tumors of unclear etiology initially detected by sonography in the noncirrhotic or cirrhotic livers of 1349 patients. Results of the DEGUM multicenter study. Ultraschall in Med 2011; 32: 598-603

[69] Strobel D, Bernatik T, Blank W et al. Diagnostic accuracy of CEUS in the differential diagnosis of small $(</=20 \mathrm{~mm})$ and subcentimetric $(</=10 \mathrm{~mm})$ focal liver lesions in comparison with histology. Results of the DEGUM multicenter trial. Ultraschall in Med 2011; 32: 593-597

[70] Bernatik T, Seitz K, Blank W et al. Unclear focal liver lesions in contrastenhanced ultrasonography - lessons to be learned from the DEGUM multicenter study for the characterization of liver tumors. Ultraschall in Med 2010; 31: 577-581

[71] Devine AS, Jackson CS, Lyons L et al. Frequency of incidental findings on computed tomography of trauma patients. West J Emerg Med 2010; 11 : 24-27

[72] Dietrich CF, Ignee A, Trojan J et al. Improved characterization of histologically proven liver tumours by contrast enhanced ultrasonography during the portal venous and specific late phase of SHU 508A. GUT 2004; 53: 401-405

[73] Sporea I, Badea R, Martie A et al. Contrast Enhanced Ultrasound for the evaluation of focal liver lesions in daily practice. A multicentre study. Med Ultrason 2012; 14: 95-100

[74] Sporea I, Badea R, Popescu A et al. Contrast-enhanced ultrasound (CEUS) for the evaluation of focal liver lesions - a prospective multicenter study of its usefulness in clinical practice. Ultraschall in Med 2014; 35: 259-266

[75] Xie L, Guang Y, Ding $\mathrm{H}$ et al. Diagnostic value of contrast-enhanced ultrasound, computed tomography and magnetic resonance imaging for focal liver lesions: a meta-analysis. Ultrasound Med Biol 2011; 37: 854861

[76] Dietrich CF, Mertens JC, Braden B et al. Contrast-enhanced ultrasound of histologically proven liver hemangiomas. Hepatology 2007; 45: 11391145

[77] Dietrich CF, Schuessler G, Trojan J et al. Differentiation of focal nodular hyperplasia and hepatocellular adenoma by contrast-enhanced ultrasound. Br J Radiol 2005; 78: 704-707

[78] Trojan J, Hammerstingl R, Engels K et al. Contrast-enhanced ultrasound in the diagnosis of malignant mesenchymal liver tumors. J Clin Ultrasound 2010; 38: 227-231

[79] Bartolotta TV, Sandonato L, Taibbi A et al. Focal liver lesions: clinical usefulness of contrast-enhanced ultrasound in the selection of surgical patients. Chir Ital 2009; 61: 295-307

[80] Westwood M, Joore M, Grutters ] et al. Contrast-enhanced ultrasound using SonoVue(R) (sulphur hexafluoride microbubbles) compared with contrast-enhanced computed tomography and contrast-enhanced magnetic resonance imaging for the characterisation of focal liver lesions and detection of liver metastases: a systematic review and costeffectiveness analysis. Health Technol Assess 2013; 17: 1-243

[81] Kaltenbach TE, Engler P, Kratzer W et al. Prevalence of benign focal liver lesions: ultrasound investigation of 45319 hospital patients. Abdom Radiol (NY) 2016; 41: 25-32

[82] Dietrich CF, Sharma M, Gibson RN et al. Fortuitously discovered liver lesions. World J Gastroenterol 2013; 19: 3173-3188

[83] Vidili G, De Sio I, D’Onofrio M et al. SIUMB guidelines and recommendations for the correct use of ultrasound in the management of patients with focal liver disease. J Ultrasound 2019; 22: 41-51

[84] Cui XW, Ignee A, Jedrzejczyk M et al. Dynamic Vascular Pattern (DVP), a quantification tool for contrast enhanced ultrasound. Z Gastroenterol 2013; 51: 427-431
[85] Sienz M, Ignee A, Dietrich CF. Reference values in abdominal ultrasound - biliopancreatic system and spleen. Z Gastroenterol 2011; 49: $845-870$

[86] Chiorean L, Cui XW, Tannapfel A et al. Benign liver tumors in pediatric patients - Review with emphasis on imaging features. World J Gastroenterol 2015; 21: 8541-8561

[87] Foschi FG, Dall'Aglio AC, Marano G et al. Role of contrast-enhanced ultrasonography in primary hepatic lymphoma. J Ultrasound Med 2010; 29: 1353-1356

[88] Inoue T, Hyodo T, Korenaga K et al. Kupffer phase image of Sonazoidenhanced US is useful in predicting a hypervascularization of non-hypervascular hypointense hepatic lesions detected on Gd-EOB-DTPAenhanced MRI: a multicenter retrospective study. J Gastroenterol 2016; 51: $144-152$

[89] Sienz M, Ignee A, Dietrich CF. Sonography today: reference values in abdominal ultrasound: aorta, inferior vena cava, kidneys. Z Gastroenterol 2012; 50: 293-315

[90] Dietrich CF, Tannapfel A, Jang HJ et al. Ultrasound Imaging of Hepatocellular Adenoma Using the New Histology Classification. Ultrasound Med Biol 2019; 45: 1-10

[91] Lamuraglia M, Escudier B, Chami L et al. To predict progression-free survival and overall survival in metastatic renal cancer treated with sorafenib: pilot study using dynamic contrast-enhanced Doppler ultrasound. Eur J Cancer 2006; 42: 2472-2479

[92] Hirche TO, Ignee A, Hirche $\mathrm{H}$ et al. Evaluation of hepatic steatosis by ultrasound in patients with chronic hepatitis $C$ virus infection. Liver Int 2007; 27: 748-757

[93] Little JM, Richardson A, Tait N. Hepatic dystychoma: a five year experience. HPB Surg 1991; 4: 291-297

[94] Sugimoto K, Moriyasu F, Saito K et al. Kupffer-phase findings of hepatic hemangiomas in contrast-enhanced ultrasound with sonazoid. Ultrasound Med Biol 2014; 40: 1089-1095

[95] Chiorean L, Caraiani C, Radzina M et al. Vascular phases in imaging and their role in focal liver lesions assessment. Clin Hemorheol Microcirc 2015; 62: 299-326

[96] Klinger C, Stuckmann G, Dietrich CF et al. Contrast-enhanced imaging in hepatic epithelioid hemangioendothelioma: retrospective study of 10 patients. Z Gastroenterol 2019; 57: 753-766

[97] Piscaglia F, Gianstefani A, Ravaioli M et al. Criteria for diagnosing benign portal vein thrombosis in the assessment of patients with cirrhosis and hepatocellular carcinoma for liver transplantation. Liver Transpl 2010; 16: 658-667

[98] Dietrich CF, Tana C, Caraiani C et al. Contrast enhanced ultrasound (CEUS) imaging of solid benign focal liver lesions. Expert Rev Gastroenterol Hepatol 2018; 12: 479-489

[99] Piscaglia F, Venturi A, Mancini M et al. Diagnostic features of real-time contrast-enhanced ultrasound in focal nodular hyperplasia of the liver. Ultraschall in Med 2010; 31: 276-282

[100] Pei XQ, Liu LZ, Xiong YH et al. Quantitative analysis of contrast-enhanced ultrasonography: differentiating focal nodular hyperplasia from hepatocellular carcinoma. Br J Radiol 2013; 86: 20120536

[101] Jones EC, Chezmar JL, Nelson RC et al. The frequency and significance of small (less than or equal to $15 \mathrm{~mm}$ ) hepatic lesions detected by CT. Am J Roentgenol 1992; 158: 535-539

[102] Lee J, Jeong WK, Lim HK et al. Focal Nodular Hyperplasia of the Liver: Contrast-Enhanced Ultrasonographic Features With Sonazoid. J Ultrasound Med 2018; 37: 1473-1480

[103] Janica J, Ustymowicz A, Lukasiewicz A et al. Comparison of contrastenhanced ultrasonography with grey-scale ultrasonography and contrast-enhanced computed tomography in diagnosing focal fatty liver infiltrations and focal fatty sparing. Adv Med Sci 2013; 58: 408-418 
[104] Dietrich CF, Jenssen C. Focal liver lesion, incidental finding. Dtsch Med Wochenschr 2012; 137: 2099-2116

[105] Catalano O, Sandomenico F, Nunziata A et al. Transient hepatic echogenicity difference on contrast-enhanced ultrasonography: sonographic sign and pitfall. J Ultrasound Med 2007; 26: 337-345

[106] Catalano O, Sandomenico F, Raso MM et al. Low mechanical index contrast-enhanced sonographic findings of pyogenic hepatic abscesses. Am J Roentgenol 2004; 182: 447-450

[107] Liu G], Lu MD, Xie XY et al. Real-time contrast-enhanced ultrasound imaging of infected focal liver lesions. J Ultrasound Med 2008; 27: 657-666

[108] Biecker E, Fischer HP, Strunk H et al. Benign hepatic tumours. Z Gastroenterol 2003; 41: 191-200

[109] Anderson SW, Kruskal JB, Kane RA. Benign hepatic tumors and iatrogenic pseudotumors. Radiographics 2009; 29: 211-229

[110] Cao BS, Li XL, Li N et al. The nodular form of hepatic tuberculosis: contrast-enhanced ultrasonographic findings with pathologic correlation. J Ultrasound Med 2010; 29: 881-888

[111] Dietrich CF, Atkinson NSS, Lee WJ et al. Never seen before? Opisthorchiasis and Clonorchiasis. Z Gastroenterol 2018; 56: 1513-1520

[112] Dietrich CF, Kabaalioglu A, Brunetti E et al. Fasciolosis. Z Gastroenterol 2015; 53: 285-290

[113] Wang Z, Xu HX, Xie XY et al. Imaging features of hepatic angiomyolipomas on real-time contrast-enhanced ultrasound. $\mathrm{Br}$ ] Radiol 2010; 83: $411-418$

[114] Corvino A, Catalano O, Setola SV et al. Contrast-enhanced ultrasound in the characterization of complex cystic focal liver lesions. Ultrasound Med Biol 2015; 41: 1301-1310

[115] Ignee A, Piscaglia F, Ott M et al. A benign tumour of the liver mimicking malignant liver disease - cholangiocellular adenoma. Scand J Gastroenterol 2009; 44: 633-636

[116] Dong Y, Wang WP, Cantisani V et al. Contrast-enhanced ultrasound of histologically proven hepatic epithelioid hemangioendothelioma. World J Gastroenterol 2016; 22: 4741-4749

[117] Cui XW, Ignee A, Woenckhaus $M$ et al. Hemangioendothelioma, an imaging challenge. Endheu 2014; 27: 34-36

[118] Lu SN, Wang LY, Chang WY et al. Abdominal sonographic screening in a single community. Gaoxiong Yi Xue Ke Xue Za Zhi 1990; 6: 643-646

[119] Forner A, Llovet JM, Bruix J. Hepatocellular carcinoma. Lancet 2012; 379: $1245-1255$

[120] Zheng SG, Xu HX, Liu LN. Management of hepatocellular carcinoma: The role of contrast-enhanced ultrasound. World J Radiol 2014; 6: 7-14

[121] Hayashi H, Nishigaki Y, Tomita E et al. Usefulness of early vascular phase images from contrast-enhanced ultrasonography using Sonazoid for the diagnosis of hypovascular hepatocellular carcinoma. Hepatol Res 2016; 46: 497-504

[122] Goto E, Masuzaki R, Tateishi R et al. Value of post-vascular phase (Kupffer imaging) by contrast-enhanced ultrasonography using Sonazoid in the detection of hepatocellular carcinoma. J Gastroenterol 2012; 47: 477-485

[123] Mandry D, Bressenot A, Galloy MA et al. Contrast-enhanced ultrasound in fibro-lamellar hepatocellular carcinoma: a case report. Ultraschall in Med 2007; 28: 547-552

[124] Arita J, Hasegawa K, Takahashi M et al. Correlation between contrastenhanced intraoperative ultrasound using Sonazoid and histologic grade of resected hepatocellular carcinoma. Am J Roentgenol 2011; 196: 1314-1321

[125] Galassi M, lavarone M, Rossi S et al. Patterns of appearance and risk of misdiagnosis of intrahepatic cholangiocarcinoma in cirrhosis at contrast enhanced ultrasound. Liver Int 2013; 33: 771-779

[126] Dong Y, Teufel A, Trojan J et al. Contrast enhanced ultrasound in mixed hepatocellular cholangiocarcinoma: Case series and review of the literature. Dig Liver Dis 2018; 50: 401-407
[127] Chen LD, Xu HX, Xie XY et al. Enhancement patterns of intrahepatic cholangiocarcinoma: comparison between contrast-enhanced ultrasound and contrast-enhanced CT. Br J Radiol 2008; 81: 881-889

[128] Schellhaas B, Pfeifer L, Kielisch C et al. Interobserver Agreement for Contrast-Enhanced Ultrasound (CEUS)-Based Standardized Algorithms for the Diagnosis of Hepatocellular Carcinoma in High-Risk Patients. Ultraschall in Med 2018; 39: 667-674

[129] Schellhaas B, Hammon M, Strobel D et al. Interobserver and intermodality agreement of standardized algorithms for non-invasive diagnosis of hepatocellular carcinoma in high-risk patients: CEUS-LI-RADS versus MRI-LI-RADS. Eur Radiol 2018; 28: 4254-4264

[130] Barreiros AP, Piscaglia F, Dietrich CF. Contrast enhanced ultrasound for the diagnosis of hepatocellular carcinoma (HCC): Comments on AASLD guidelines. J Hepatol 2012; 57: 930-932

[131] Dietrich CF, Cui XW, Boozari B et al. Contrast-enhanced ultrasound (CEUS) in the diagnostic algorithm of hepatocellular and cholangiocelIular carcinoma, comments on the AASLD guidelines. Ultraschall in Med 2012; 33: S57-S66

[132] Leoni S, Piscaglia F, Golfieri R et al. The impact of vascular and nonvascular findings on the noninvasive diagnosis of small hepatocellular carcinoma based on the EASL and AASLD criteria. Am J Gastroenterol 2010; 105: 599-609

[133] Piscaglia F, Wilson SR, Lyshchik A et al. American College of Radiology Contrast Enhanced Ultrasound Liver Imaging Reporting and Data System (CEUS LI-RADS) for the diagnosis of Hepatocellular Carcinoma: a pictorial essay. Ultraschall in Med 2017; 38: 320-324

[134] Kono Y, Lyshchik A, Cosgrove D et al. Contrast Enhanced Ultrasound (CEUS) Liver Imaging Reporting and Data System (LI-RADS(R)): the official version by the American College of Radiology (ACR). Ultraschall in Med 2017; 38: 85-86

[135] Kim TK, Noh SY, Wilson SR et al. Contrast-enhanced ultrasound (CEUS) liver imaging reporting and data system (LI-RADS) 2017 - a review of important differences compared to the CT/MRI system. Clin Mol Hepatol 2017; 23: 280-289

[136] Zech C]. Incidental livers lesions - a modern approach. MMW Fortschr Med 2011; 153: 41-44; quiz 45

[137] Frydrychowicz A, Lubner MG, Brown J] et al. Hepatobiliary MR imaging with gadolinium-based contrast agents. J Magn Reson Imaging 2012; 35: 492-511

[138] Xu HX, Chen LD, Liu LN et al. Contrast-enhanced ultrasound of intrahepatic cholangiocarcinoma: correlation with pathological examination. Br J Radiol 2012; 85: 1029-1037

[139] Dietrich CF, Serra C, Jedrejczyk M. Chapter 2, Ultrasound of liver. In: Dietrich CF, ed; EFSUMB Europen Course Book. London: Latimer Trend \& Company Ltd; 2012: 27-55

[140] Ying L, Lin X, Xie ZL et al. Clinical utility of acoustic radiation force impulse imaging for identification of malignant liver lesions: a metaanalysis. Eur Radiol 2012; 22: 2798-2805

[141] Hatanaka K, Kudo M, Minami Y et al. Differential diagnosis of hepatic tumors: value of contrast-enhanced harmonic sonography using the newly developed contrast agent, Sonazoid. Intervirology 2008; 51 (Suppl. 1): 61-69

[142] Trenker C, Kunsch S, Michl P et al. Contrast-enhanced ultrasound (CEUS) in hepatic lymphoma: retrospective evaluation in 38 cases. Ultraschall in Med 2014; 35: 142-148

[143] Heller E, Gorg C. Focal liver lesions in patients with malignant haematological disease: value of B-mode ultrasound in comparison to contrast-enhanced ultrasound - a retrospective study with $\mathrm{N}=61$ patients. Z Gastroenterol 2013; 51: 558-567

[144] Zhang YL, Yuan L, Shen H et al. Haemorrhagic hepatic cysts mimicking biliary cystadenoma. World J Gastroenterol 2009; 15: 4601-4603 
[145] Corvino A, Catalano O, Corvino F et al. Diagnostic Performance and Confidence of Contrast-Enhanced Ultrasound in the Differential Diagnosis of Cystic and Cysticlike Liver Lesions. Am J Roentgenol 2017; 209: W119-W127

[146] Vachha B, Sun MR, Siewert B et al. Cystic lesions of the liver. Am J Roentgenol 2011; 196: W355-W366

[147] Cha EY, Kim KW, Choi Y] et al. Multicystic cavernous haemangioma of the liver: Ultrasonography, CT, MR appearances and pathologic correlation. $\mathrm{Br}$ J Radiol 2008; 81: e37-e39

[148] Barreiros AP, Chiorean L, Braden B et al. Ultrasound in rare diffuse liver disease. Z Gastroenterol 2014; 52: 1247-1256

[149] Lin MX, Xu HX, Lu MD et al. Diagnostic performance of contrast-enhanced ultrasound for complex cystic focal liver lesions: Blinded liver study. Eur Radiol 2009; 19: 358-369

[150] Mork H, Ignee A, Schuessler G et al. Analysis of neuroendocrine tumour metastases in the liver using contrast enhanced ultrasonography. Scand J Gastroenterol 2007; 42: 652-662

[151] Piscaglia F, Lencioni R, Sagrini E et al. Characterization of focal liver lesions with contrast-enhanced ultrasound. Ultrasound Med Biol 2010; 36: $531-550$

[152] Wang JY, Feng SY, Xu JW et al.. Usefulness of the Contrast-Enhanced Ultrasound Liver Imaging Reporting and Data System in Diagnosing Focal Liver Lesions by Inexperienced Radiologists. J Ultrasound Med 2020; Feb 20 doi:10.1002/jum.15242

[153] Rodgers SK, Fetzer DT, Gabriel $\mathrm{H}$ et al. Role of US LI-RADS in the LI-RADS Algorithm. Radiographics 2019; 39: 690-708

[154] Dietrich CF, Potthoff A, Helmberger T et al. Contrast-enhanced ultrasound: Liver Imaging Reporting and Data System (CEUS LI-RADS). Z Gastroenterol 2018; 56: 499-506

[155] Kono Y, Sirlin CB, Fetzer DT et al. Time to Clarify Common Misconceptions about the Liver Imaging Reporting and Data System for Contrastenhanced US. Radiology 2020; 295: 245-247

[156] Lyshchik A, Kono Y, Dietrich CF et al. Contrast-enhanced ultrasound of the liver: technical and lexicon recommendations from the ACR CEUS LI-RADS working group. Abdom Radiol (NY) 2018; 43: 861-879

[157] Terzi E, lavarone M, Pompili M et al. Contrast ultrasound LI-RADS LR-5 identifies hepatocellular carcinoma in cirrhosis in a multicenter restropective study of 1006 nodules. J Hepatol 2018; 68: 485-492

[158] Sangiovanni A, Manini MA, lavarone $M$ et al. The diagnostic and economic impact of contrast imaging techniques in the diagnosis of small hepatocellular carcinoma in cirrhosis. Gut 2010; 59: 638-644

[159] Boozari B, Soudah B, Rifai K et al. Grading of hypervascular hepatocellular carcinoma using late phase of contrast enhanced sonography - a prospective study. Dig Liver Dis 2011; 43: 484-490

[160] Fan ZH, Chen MH, Dai Y et al. Evaluation of primary malignancies of the liver using contrast-enhanced sonography: correlation with pathology. Am J Roentgenol 2006; 186: 1512-1519

[161] lavarone M, Sangiovanni A, Forzenigo LV et al. Diagnosis of hepatocellular carcinoma in cirrhosis by dynamic contrast imaging: the importance of tumor cell differentiation. Hepatology 2010; 52: 1723-1730

[162] Jang HJ, Kim TK, Burns PN et al. Enhancement patterns of hepatocellular carcinoma at contrast-enhanced US: comparison with histologic differentiation. Radiology 2007; 244: 898-906

[163] Wildner D, Bernatik T, Greis C et al. CEUS in hepatocellular carcinoma and intrahepatic cholangiocellular carcinoma in 320 patients - early or late washout matters: a subanalysis of the DEGUM multicenter trial. Ultraschall in Med 2015; 36: 132-139

[164] Chen MH, Dai Y, Yan K et al. The role of contrast-enhanced ultrasound on the diagnosis of small hepatocellular carcinoma $(<1=3 \mathrm{~cm})$ in patients with cirrhosis. Hepatol Res 2006; 35: 281-288
[165] Dietrich CF, Kono Y, Cosgrove D et al. Contrast-Enhanced Ultrasound: Liver Imaging Reporting and Data System (CEUS LI-RADS). In: Solutions in contrast imaging: Solutions in CONTRAST IMAGING 2016

[166] Schellhaas B, Gortz RS, Pfeifer L et al. Diagnostic accuracy of contrastenhanced ultrasound for the differential diagnosis of hepatocellular carcinoma: ESCULAP versus CEUS-LI-RADS. Eur J Gastroenterol Hepatol 2017; 29: 1036-1044

[167] Tarantino L, Francica G, Sordelli I et al. Diagnosis of benign and malignant portal vein thrombosis in cirrhotic patients with hepatocellular carcinoma: color Doppler US, contrast-enhanced US, and fine-needle biopsy. Abdom Imaging 2006; 31: 537-544

[168] Chammas MC, Oliveira AC, MJ DA et al. Characterization of Malignant Portal Vein Thrombosis with Contrast-Enhanced Ultrasonography. Ultrasound Med Biol 2019; 45: 50-55

[169] Raza SA, Jang HJ, Kim TK. Differentiating malignant from benign thrombosis in hepatocellular carcinoma: Contrast-enhanced ultrasound. Abdominal Imaging 2014; 39: 153-161

[170] Dănilă M, Sporea I, Popescu A et al. The value of contrast enhanced ultrasound in the evaluation of the nature of portal vein thrombosis. Med Ultrason 2011; 13: 102-107

[171] Song ZZ, Huang M, Jiang TA et al. Diagnosis of portal vein thrombosis discontinued with liver tumors in patients with liver cirrhosis and tumors by contrast-enhanced US: a pilot study. Eur J Radiol 2010; 75: 185-188

[172] Ueno N, Kawamura H, Takahashi H et al. Characterization of portal vein thrombus with the use of contrast-enhanced sonography. Journal of Ultrasound in Medicine 2006; 25: 1147-1152

[173] Rossi S, Rosa L, Ravetta V et al. Contrast-enhanced versus conventional and color Doppler sonography for the detection of thrombosis of the portal and hepatic venous systems. Am J Roentgenol 2006; 186: $763-$ 773

[174] Sorrentino P, D’Angelo S, Tarantino L et al. Contrast-enhanced sonography versus biopsy for the differential diagnosis of thrombosis in hepatocellular carcinoma patients. World ] Gastroenterol 2009; 15: 2245-2251

[175] Torzilli G, Del Fabbro D, Olivari N et al. Contrast-enhanced ultrasonography during liver surgery. Br J Surg 2004; 91: 1165-1167

[176] Torzilli G, Palmisano A, Del Fabbro D et al Contrast-enhanced intraoperative ultrasonography during surgery for hepatocellular carcinoma in liver cirrhosis: is it useful or useless? A prospective cohort study of our experience. Ann Surg Oncol 2007; 14: 1347-1355

[177] Torzilli G, Botea F, Donadon M et al. Criteria for the selective use of contrast-enhanced intra-operative ultrasound during surgery for colorectal liver metastases. HPB (Oxford) 2014; 16: 994-1001

[178] Fioole B, de Haas RJ, Wicherts DA et al. Additional value of contrast enhanced intraoperative ultrasound for colorectal liver metastases. Eur J Radiol 2008; 67: 169-176

[179] Nakano H, Ishida Y, Hatakeyama T et al. Contrast-enhanced intraoperative ultrasonography equipped with late Kupffer-phase image obtained by sonazoid in patients with colorectal liver metastases. World J Gastroenterol 2008; 14: 3207-3211

[180] Arita J, Takahashi M, Hata S et al. Usefulness of contrast-enhanced intraoperative ultrasound using Sonazoid in patients with hepatocellular carcinoma. Ann Surg 2011; 254: 992-999

[181] Huf S, Platz Batista da Silva N, Wiesinger I et al. Analysis of Liver Tumors Using Preoperative and Intraoperative Contrast-Enhanced Ultrasound (CEUS/IOCEUS) by Radiologists in Comparison to Magnetic Resonance Imaging and Histopathology. Rofo 2017; 189: 431-440

[182] Leen E, Ceccotti P, Moug SJ et al. Potential value of contrast-enhanced intraoperative ultrasonography during partial hepatectomy for metastases: an essential investigation before resection? Ann Surg 2006; 243 : 236-240 
[183] Jones RP, Vauthey JN, Adam R et al. Effect of specialist decision-making on treatment strategies for colorectal liver metastases. Br J Surg 2012; 99: 1263-1269

[184] Lorentzen T, Nolsoe CP, Ewertsen C et al. EFSUMB Guidelines on Interventional Ultrasound (INVUS), Part I. General Aspects (Short Version). Ultraschall in Med 2015; 36: 464-472

[185] Sidhu PS, Brabrand K, Cantisani V et al. EFSUMB Guidelines on Interventional Ultrasound (INVUS), Part II. Diagnostic Ultrasound-Guided Interventional Procedures (Short Version). Ultraschall in Med 2015; 36 : 566-580

[186] Francica G, Meloni MF, de Sio I et al. Biopsy of Liver Target Lesions under Contrast-Enhanced Ultrasound Guidance - A Multi-Center Study. Ultraschall in Med 2018; 39: 448-453

[187] Wu W, Chen MH, Yin SS et al. The role of contrast-enhanced sonography of focal liver lesions before percutaneous biopsy. Am J Roentgenol 2006; 187: 752-761

[188] Cao X, Liu Z, Zhou X et al. Usefulness of real-time contrast-enhanced ultrasound guided coaxial needle biopsy for focal liver lesions. Abdom Radiol (NY) 2019; 44: 310-317

[189] Sparchez Z, Radu P, Kacso G et al. Prospective comparison between real time contrast enhanced and conventional ultrasound guidance in percutaneous biopsies of liver tumors. Med Ultrason 2015; 17: 456463

[190] Nolsoe CP, Nolsoe AB, Klubien J et al. Use of Ultrasound Contrast Agents in Relation to Percutaneous Interventional Procedures: A Systematic Review and Pictorial Essay. J Ultrasound Med 2018; 37: 13051324

[191] Bang N, Bachmann Nielsen M, Vejborg I et al. Clinical report: contrast enhancement of tumor perfusion as a guidance for biopsy. Eur J Ultrasound 2000; 12: 159-161

[192] Eso Y, Takai A, Takeda $\mathrm{H}$ et al. Sonazoid-enhanced ultrasonography guidance improves the quality of pathological diagnosis in the biopsy of focal hepatic lesions. Eur J Gastroenterol Hepatol 2016; 28: 14621467

[193] Skjoldbye B, Pedersen MH, Struckmann J et al. Improved detection and biopsy of solid liver lesions using pulse-inversion ultrasound scanning and contrast agent infusion. Ultrasound Med Biol 2002; 28: 439-444

[194] Schlottmann K, Klebl F, Zorger N et al. Contrast-enhanced ultrasound allows for interventions of hepatic lesions which are invisible on convential B-mode. Z Gastroenterol 2004; 42: 303-310

[195] Yoon SH, Lee KH, Kim SY et al. Real-time contrast-enhanced ultrasound-guided biopsy of focal hepatic lesions not localised on B-mode ultrasound. Eur Radiol 2010; 20: 2047-2056

[196] Park HS, Kim YJ, Yu MH et al. Real-time contrast-enhanced sonographically guided biopsy or radiofrequency ablation of focal liver lesions using perflurobutane microbubbles (sonazoid): value of Kupffer-phase imaging. J Ultrasound Med 2015; 34: 411-421

[197] Kang TW, Lee MW, Song KD et al. Added Value of Contrast-Enhanced Ultrasound on Biopsies of Focal Hepatic Lesions Invisible on Fusion Imaging Guidance. Korean J Radiol 2017; 18: 152-161

[198] Kang HJ, Kim JH, Lee SM et al. Additional value of contrast-enhanced ultrasonography for fusion-guided, percutaneous biopsies of focal liver lesions: prospective feasibility study. Abdom Radiol (NY) 2018; 43: 3279-3287

[199] Lorentzen T, Nolsoe CP, Ewertsen C et al. EFSUMB Guidelines on Interventional Ultrasound (INVUS), Part I. General Aspects (long Version). Ultraschall in Med 2015; 36: E1-E14

[200] Yusuf GT, Fang C, Huang DY et al. Endocavitary contrast enhanced ultrasound (CEUS): a novel problem solving technique. Insights Imaging 2018; 9: 303-311

[201] Cui XW, Ignee A, Baum U et al. Feasibility and usefulness of using swallow contrast-enhanced ultrasound to diagnose Zenker's diverticulum: preliminary results. Ultrasound Med Biol 2015; 41: 975-981
[202] Cui XW, Ignee A, Maros T et al. Feasibility and Usefulness of Intra-Cavitary Contrast-Enhanced Ultrasound in Percutaneous Nephrostomy. Ultrasound Med Biol 2016; 42: 2180-2188

[203] Heinzmann A, Muller T, Leitlein J et al. Endocavitary contrast enhanced ultrasound (CEUS)-work in progress. Ultraschall in Med 2012; 33: 76-84

[204] Ignee A, Schuessler G, Cui XW et al. Intracavitary contrast medium ultrasound - different applications, a review of the literature ad future prospects. Ultraschall in Med 2013; 34: 504-525; quiz 526-508

[205] Ignee A, Jenssen C, Cui XW et al. Intracavitary contrast-enhanced ultrasound in abscess drainage-feasibility and clinical value. Scand J Gastroenterol 2016; 51: 41-47

[206] Ignee A, Cui X, Schuessler G et al. Percutaneous transhepatic cholangiography and drainage using extravascular contrast enhanced ultrasound. Z Gastroenterol 2015; 53: 385-390

[207] Ignee A, Baum U, Schuessler G et al. Contrast-enhanced ultrasoundguided percutaneous cholangiography and cholangiodrainage (CEUS-PTCD). Endoscopy 2009; 41: 725-726

[208] Urade T, Fukumoto T, Tanaka M et al. Contrast-enhanced intraoperative ultrasonic cholangiography for real-time biliary navigation in hepatobiliary surgery. J Am Coll Surg 2014; 218: e43-e50

[209] Chopra SS, Eisele R, Stelter L et al. Contrast enhanced ultrasound cholangiography via T-tube following liver transplantation. Ann Transplant 2012; 17: 108-112

[210] Daneshi M, Rajayogeswaran B, Peddu P et al. Demonstration of an occult biliary-arterial fistula using percutaneous contrast-enhanced ultrasound cholangiography in a transplanted liver. J Clin Ultrasound 2014; 42: 108-111

[211] Mao R, Xu E], Li K et al. Usefulness of contrast-enhanced ultrasound in the diagnosis of biliary leakage following T-tube removal. J Clin Ultrasound 2010; 38: 38-40

[212] Xu EJ, Mao R, Zheng RQ et al. Three-dimensional contrast-enhanced ultrasonic cholangiography: a new technique for delineation of the biliary tract in a liver donor. Liver Transpl 2009; 15: 1154-1156

[213] Zheng RQ, Chen GH, Xu EJ et al. Evaluating biliary anatomy and variations in living liver donors by a new technique: three-dimensional contrast-enhanced ultrasonic cholangiography. Ultrasound Med Biol 2010 36: 1282-1287

[214] Velosa M, Lopes S, Castro R et al. Cholecystoduodenal fistula diagnosed with contrast-enhanced endoscopic ultrasound. Endoscopy 2013; 45 (Suppl. 2): E18-E19

[215] Zuber-Jerger I, Endlicher E, Scholmerich J et al. Endoscopic retrograde cholangiography with contrast ultrasonography. Endoscopy 2008; 40 (Suppl. 2): E202

[216] Luyao Z, Xiaoyan X, Huixiong X et al. Percutaneous ultrasound-guided cholangiography using microbubbles to evaluate the dilated biliary tract: initial experience. Eur Radiol 2012; 22: 371-378

[217] Girlich C, Buttner R, Schacherer D et al. Contrast-enhanced sonographic drainage control: a feasibility study. Z Gastroenterol 2011; 49: $1470-1474$

[218] Muller T, Blank W, Leitlein J et al. Endocavitary contrast-enhanced ultrasound: a technique whose time has come? J Clin Ultrasound 2015; 43: $71-80$

[219] Lencioni R, Crocetti L. Local-regional treatment of hepatocellular carcinoma. Radiology 2012; 262: 43-58

[220] Liu F, Yu X, Liang P et al. Ultrasonography-guided percutaneous microwave ablation for large hepatic cavernous haemangiomas. Int J Hyperthermia 2018; 34: 1061-1066

[221] Francica G, Meloni MF, Riccardi L et al. Ablation treatment of primary and secondary liver tumors under contrast-enhanced ultrasound guidance in field practice of interventional ultrasound centers. A multicenter study. Eur J Radiol 2018; 105: 96-101 
[222] Liu F, Yu X, Liang P et al. Contrast-enhanced ultrasound-guided microwave ablation for hepatocellular carcinoma inconspicuous on conventional ultrasound. Int J Hyperthermia 2011; 27: 555-562

[223] Chan AK, Hegarty C, Klass D et al. The Role of Contrast-enhanced Ultrasound in Guiding Radiofrequency Ablation of Hepatocellular Carcinoma: A Retrospective Study. Can Assoc Radiol J 2015; 66: 171 178

[224] Bo XW, Xu HX, Wang D et al. Fusion imaging of contrast-enhanced ultrasound and contrast-enhanced CT or MRI before radiofrequency ablation for liver cancers. Br J Radiol 2016; 89: 20160379

[225] Xu E, Long Y, Li K et al. Comparison of CT/MRI-CEUS and US-CEUS fusion imaging techniques in the assessment of the thermal ablation of liver tumors. Int J Hyperthermia 2019; 35: 159-167

[226] Meloni MF, Andreano A, Franza E et al. Contrast enhanced ultrasound: Should it play a role in immediate evaluation of liver tumors following thermal ablation? Eur J Radiol 2012; 81: e897-e902

[227] Mauri G, Porazzi E, Cova L et al. Intraprocedural contrast-enhanced ultrasound (CEUS) in liver percutaneous radiofrequency ablation: clinical impact and health technology assessment. Insights Imaging 2014; 5: 209-216

[228] Numata K, Fukuda H, Morimoto $\mathrm{M}$ et al. Use of fusion imaging combining contrast-enhanced ultrasonography with a perflubutane-based contrast agent and contrast-enhanced computed tomography for the evaluation of percutaneous radiofrequency ablation of hypervascular hepatocellular carcinoma. Eur J Radiol 2012; 81: 2746-2753

[229] Zhong-Zhen S, Kai L, Rong-Qin Z et al. A feasibility study for determining ablative margin with 3D-CEUS-CT/MR image fusion after radiofrequency ablation of hepatocellular carcinoma. Ultraschall in Med 2012; 33: E250-E255

[230] Makino Y, Imai Y, Igura T et al. Feasibility of Extracted-Overlay Fusion Imaging for Intraoperative Treatment Evaluation of Radiofrequency Ablation for Hepatocellular Carcinoma. Liver Cancer 2016; 5: 269-279

[231] Li K, Su ZZ, Xu EJ et al. Improvement of ablative margins by the intraoperative use of CEUS-CT/MR image fusion in hepatocellular carcinoma. BMC Cancer 2016; 16: 277

[232] Ye J, Huang G, Zhang X et al. Three-dimensional contrast-enhanced ultrasound fusion imaging predicts local tumor progression by evaluating ablative margin of radiofrequency ablation for hepatocellular carcinoma: a preliminary report. Int J Hyperthermia 2019; 36: 55-64

[233] Minami Y, Kudo M, Chung $\mathrm{H}$ et al. Contrast harmonic sonographyguided radiofrequency ablation therapy versus B-mode sonography in hepatocellular carcinoma: prospective randomized controlled trial. Am J Roentgenol 2007; 188: 489-494

[234] Lencioni R, Llovet JM. Modified RECIST (mRECIST) assessment for hepatocellular carcinoma. Semin Liver Dis 2010; 30: 52-60

[235] Choi D, Lim HK, Lee WJ et al. Early assessment of the therapeutic response to radio frequency ablation for hepatocellular carcinoma: utility of gray scale harmonic ultrasonography with a microbubble contrast agent. J Ultrasound Med 2003; 22: 1163-1172

[236] Zheng SG, Xu HX, Lu MD et al. Role of contrast-enhanced ultrasound in follow-up assessment after ablation for hepatocellular carcinoma. World J Gastroenterol 2013; 19: 855-865

[237] Kisaka Y, Hirooka M, Kumagi T et al. Usefulness of contrast-enhanced ultrasonography with abdominal virtual ultrasonography in assessing therapeutic response in hepatocellular carcinoma treated with radiofrequency ablation. Liver Int 2006; 26: 1241-1247

[238] Qu P, Yu X, Liang P et al. Contrast-enhanced ultrasound in the characterization of hepatocellular carcinomas treated by ablation: comparison with contrast-enhanced magnetic resonance imaging. Ultrasound Med Biol 2013; 39: 1571-1579

[239] Frieser M, Kiesel J, Lindner A et al. Efficacy of contrast-enhanced US versus CT or MRI for the therapeutic control of percutaneous radiofre- quency ablation in the case of hepatic malignancies. Ultraschall in Med 2011; 32: 148-153

[240] Chen MH, Yang W, Yan K et al. Large liver tumors: protocol for radiofrequency ablation and its clinical application in 110 patients-mathematic model, overlapping mode, and electrode placement process. Radiology 2004; 232: 260-271

[241] Ferrara N, Kerbel RS. Angiogenesis as a therapeutic target. Nature 2005; 438: 967-974

[242] Kessler T, Bayer M, Schwoppe C et al. Compounds in clinical Phase III and beyond. Recent Results Cancer Res 2010; 180: 137-163

[243] Dietrich CF, Averkiou MA, Correas JM et al. An EFSUMB introduction into Dynamic Contrast-Enhanced Ultrasound (DCE-US) for quantification of tumour perfusion. Ultraschall in Med 2012; 33: 344-351

[244] Bos LJ, Piek J], Spaan JA. Background subtraction from time-intensity curves in videodensitometry: a pitfall in flow assessment using contrast echocardiography. Ultrasound Med Biol 1995; 21: 1211-1218

[245] Peronneau P, Lassau N, Leguerney I et al. Contrast ultrasonography: necessity of linear data processing for the quantification of tumor vascularization. Ultraschall in Med 2010; 31: 370-378

[246] Cosgrove D, Lassau N. Imaging of perfusion using ultrasound. Eur ] Nucl Med Mol Imaging 2010; 37 (Suppl. 1): S65-S85

[247] Therasse P, Arbuck SG, Eisenhauer EA et al. New guidelines to evaluate the response to treatment in solid tumors. European Organization for Research and Treatment of Cancer, National Cancer Institute of the United States, National Cancer Institute of Canada. J Natl Cancer Inst 2000; 92: 205-216

[248] World Health Organisation. WHO handbook for reporting results of cancer treatment. Geneva, Switzerland. 1979 WHO Offset Publication No. 48. Available at: https://apps.who.int/iris/handle/10665/37200 Accessed on June 1, 2019.

[249] De Giorgi U, Aliberti C, Benea G et al. Effect of angiosonography to monitor response during imatinib treatment in patients with metastatic gastrointestinal stromal tumors. Clin Cancer Res 2005; 11: 61716176

[250] Lassau N, Chami L, Chebil M et al. Dynamic contrast-enhanced ultrasonography (DCE-US) and anti-angiogenic treatments. Discov Med 2011; 11: $18-24$

[251] Lassau N, Chami L, Koscielny S et al. Quantitative functional imaging by Dynamic Contrast Enhanced Ultrasonography (DCE-US) in GIST patients treated with masatinib. Invest New Drugs 2012; 30: 765-771

[252] Lassau N, Koscielny S, Chami L et al. Advanced Hepatocellular Carcinoma: Early Evaluation of Response to Bevacizumab Therapy at Dynamic Contrast-enhanced US with Quantification-Preliminary Results. Radiology 2010; 258: 291-300

[253] Lassau N, Lamuraglia M, Chami L et al. Gastrointestinal stromal tumors treated with imatinib: monitoring response with contrast-enhanced sonography. Am J Roentgenol 2006; 187: 1267-1273

[254] Frampas E, Lassau N, Zappa M et al. Advanced Hepatocellular Carcinoma: early evaluation of response to targeted therapy and prognostic value of Perfusion CT and Dynamic Contrast Enhanced-Ultrasound. Preliminary results. Eur J Radiol 2013; 82: e205-e211

[255] Lazar V, Lassau N, Meurice G et al. Sorafenib plus dacarbazine in solid tumors: a phase I study with dynamic contrast-enhanced ultrasonography and genomic analysis of sequential tumor biopsy samples. Invest New Drugs 2014; 32: 312-322

[256] Lo GM, Al Zahrani H, Jang H] et al. Detection of Early Tumor Response to Axitinib in Advanced Hepatocellular Carcinoma by Dynamic Contrast Enhanced Ultrasound. Ultrasound Med Biol 2016; 42: 1303-1311

[257] Lassau N, Coiffier B, Faivre L et al. Study of Intrapatient Variability and Reproducibility of Quantitative Tumor Perfusion Parameters Evaluated With Dynamic Contrast-Enhanced Ultrasonography. Invest Radiol 2017; 52: 148-154 
[258] Wu Z, Yang X, Chen L et al. Anti-angiogenic therapy with contrast-enhanced ultrasound in colorectal cancer patients with liver metastasis. Medicine (Baltimore) 2017; 96: e6731

[259] Hudson JM, Bailey C, Atri M et al. The prognostic and predictive value of vascular response parameters measured by dynamic contrast-enhancedCT, -MRI and -US in patients with metastatic renal cell carcinoma receiving sunitinib. Eur Radiol 2018; 28: 2281-2290

[260] Hudson JM, Williams R, Tremblay-Darveau C et al. Dynamic contrast enhanced ultrasound for therapy monitoring. Eur J Radiol 2015; 84: 1650-1657

[261] Lencioni R. European Federation of Societies for Ultrasound in M, Biology. Impact of European Federation of Societies for Ultrasound in Medicine and Biology (EFSUMB) guidelines on the use of contrast agents in liver ultrasound. Eur Radiol 2006; 16: 1610-1613

[262] Seitz K. EFSUMB-guidelines for CEUS are directive and effective. Ultraschall in Med 2010; 31: 225-227

[263] Lassau N, Bonastre J, Kind M et al. Validation of Dynamic Contrast-Enhanced Ultrasound in Predicting Outcomes of Antiangiogenic Therapy for Solid Tumors: The French Multicenter Support for Innovative and Expensive Techniques Study. Invest Radiol 2014; 49 (12): 794-800

[264] O'Connor JP, Aboagye EO, Adams JE et al. Imaging biomarker roadmap for cancer studies. Nat Rev Clin Oncol 2017; 14: 169-186

[265] Jacob J, Deganello A, Sellars ME et al. Contrast enhanced ultrasound (CEUS) characterization of grey-scale sonographic indeterminate focal liver lesions in pediatric practice. Ultraschall in Med 2013; 34: 529-540

[266] Fang C, Bernardo S, Sellars ME et al. Contrast-enhanced ultrasound in the diagnosis of pediatric focal nodular hyperplasia and hepatic adenoma: interobserver reliability. Pediatr Radiol 2019; 49: 82-90

[267] Menichini G, Sessa B, Trinci M et al. Accuracy of contrast-enhanced ultrasound (CEUS) in the identification and characterization of traumatic solid organ lesions in children: a retrospective comparison with baseline US and CE-MDCT. Radiol Med 2015; 120: 989-1001

[268] Durkin N, Deganello A, Sellars ME et al. Post-traumatic liver and splenic pseudoaneurysms in children: Diagnosis, management, and follow-up screening using contrast enhanced ultrasound (CEUS). J Pediatr Surg 2016; 51: 289-292

[269] Valentino M, Serra C, Pavlica P et al. Blunt abdominal trauma: diagnostic performance of contrast-enhanced US in children-initial experience. Radiology 2008; 246: 903-909
[270] Bonini G, Pezzotta G, Morzenti C et al. Contrast-enhanced ultrasound with SonoVue in the evaluation of postoperative complications in pediatric liver transplant recipients. J Ultrasound 2007; 10: 99-106

[271] Torres A, Koskinen SK, Gjertsen H et al. Contrast-Enhanced Ultrasound for identifying circulatory complications after liver transplants in children. Pediatr Transplant 2019; 23: e13327

[272] Rennert J, Dornia C, Georgieva M et al. Identification of early complications following liver transplantation using contrast enhanced ultrasound (CEUS). First results. J Gastrointestin Liver Dis 2012; 21: 407-412

[273] Piskunowicz M, Kosiak W, Batko T et al. Safety of intravenous application of second-generation ultrasound contrast agent in children: prospective analysis. Ultrasound Med Biol 2015; 41: 1095-1099

[274] Yusuf GT, Sellars ME, Deganello A et al. Retrospective Analysis of the Safety and Cost Implications of Pediatric Contrast-Enhanced Ultrasound at a Single Center. Am J Roentgenol 2017; 208: 446-452

[275] American Institute of Ultrasound in Medicine. AlUM Practice Parameter for Documentation of an Ultrasound Examination. J Ultrasound Med 2020; 39: E1-E4

[276] Piscaglia F, Nolsoe C, Dietrich CF et al. The EFSUMB Guidelines and Recommendations on the Clinical Practice of Contrast Enhanced Ultrasound (CEUS): update 2011 on non-hepatic applications. Ultraschall in Med 2012; 33: 33-59

[277] Stenman C, Jamil S, Thorelius L et al. Do radiologists agree on findings in radiographer-acquired sonographic examinations? J Ultrasound Med 2013; 32: 513-518

[278] Gilja OH. Report Education and Professional Standard Committee. In EFSUMB Newsletter. Ultraschall in Med 2009; 30: 86-87

[279] Dietrich CF, Ignee A, Greis C et al. Artifacts and pitfalls in contrast-enhanced ultrasound of the liver. Ultraschall in Med 2014; 35: 108-125; quiz 126-107

[280] Dietrich CF, Ignee A, Hocke M et al. Pitfalls and artefacts using contrast enhanced ultrasound. Z Gastroenterol 2011; 49: 350-356

[281] Fetzer DT, Rafailidis V, Peterson C et al. Artifacts in contrast-enhanced ultrasound: a pictorial essay. Abdom Radiol (NY) 2018; 43: 977-997

[282] Cui XW, Ignee A, Hocke M et al. Prolonged heterogeneous liver enhancement on contrast-enhanced ultrasound. Ultraschall in Med 2014; 35: $246-252$ 